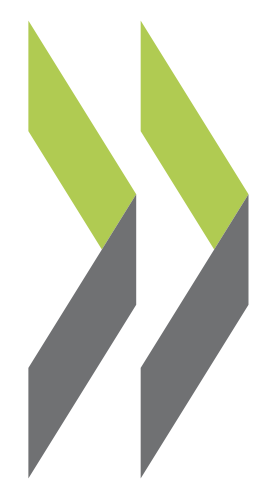

OECD Economics Department Working Papers No. 1231

Incorporating Anchored Inflation Expectations in the Phillips Curve and in the Derivation of OECD Measures of Equilibrium Unemployment
Elena Rusticelli, David Turner, Maria Chiara Cavalleri 
Organisation de Coopération et de Développement Économiques

Organisation for Economic Co-operation and Development

28-May-2015

ECONOMICS DEPARTMENT

English - Or. English

INCORPORATING ANCHORED INFLATION EXPECTATIONS IN THE PHILLIPS CURVE AND IN THE DERIVATION OF OECD MEASURES OF EQUILIBRIUM UNEMPLOYMENT

ECONOMICS DEPARTMENT WORKING PAPERS No. 1231

By Elena Rusticelli, David Turner and Maria Chiara Cavalleri

OECD Working Papers should not be reported as representing the official views of the OECD or of its member countries. The opinions expressed and arguments employed are those of the author(s).

Authorised for publication by Jean-Luc Schneider, Deputy Director, Policy Studies Branch, Economics Department.

All Economics Department Working Papers are available at www.oecd.org/eco/workingpapers

\section{JT03377288}

Complete document available on OLIS in its original format

This document and any map included herein are without prejudice to the status of or sovereignty over any territory, to the delimitation of international frontiers and boundaries and to the name of any territory, city or area. 
OECD Working Papers should not be reported as representing the official views of the OECD or of its member countries. The opinions expressed and arguments employed are those of the author(s).

Working Papers describe preliminary results or research in progress by the author(s) and are published to stimulate discussion on a broad range of issues on which the OECD works.

Comments on Working Papers are welcomed, and may be sent to the Economics Department, OECD, 2 rue André-Pascal, 75775 Paris Cedex 16, France.

\section{(C) OECD (2015)}

You can copy, download or print OECD content for your own use, and you can include excerpts from OECD publications, databases and multimedia products in your own documents, presentations, blogs, websites and teaching materials, provided that suitable acknowledgment of OECD as source and copyright owner is given. All requests for commercial use and translation rights should be submitted to rights@oecd.org 
ECO/WKP(2015)49

\section{ABSTRACT/RÉSUMÉ \\ Incorporating Anchored Inflation Expectations in the Phillips Curve and in the Derivation of OECD Measures of Equilibrium Unemployment}

Inflation has become much less sensitive to movements in unemployment in recent decades. A common explanation for this change is that inflation expectations have become better anchored as a consequence of credible inflation targeting by central banks. In order to evaluate this hypothesis, the paper compares two competing empirical specifications across all OECD economies, where competing specifications correspond to the 'former' and 'new' specification for deriving measures of the unemployment gap which underlie the OECD's Economic Outlook projections. The former OECD specification can be characterised as a traditional 'backward-looking' Phillips curve, where current inflation is partly explained by an autoregressive distributed lag process of past inflation representing both inertia and inflation expectations formed on the basis of recent inflation outcomes. Conversely, the new approach adjusts this specification to incorporate the notion that inflation expectations are anchored around the central bank's inflation objective. The main finding of the paper is that the latter approach systematically out-performs the former for an overwhelming majority of OECD countries over a recent sample period. Relative to the backward-looking specification, the anchored expectations approach also tends to imply larger unemployment gaps for those countries for which actual unemployment has increased the most. Moreover, the anchored expectations Phillips curve reduces real-time revisions to the unemployment gap, although these still remain uncomfortably large, in the case of countries where there have been large changes in unemployment.

JEL classification codes: C22, E24, E31, J64

Keywords: Anchored expectations, Phillips curve, equilibrium unemployment, real-time revisions.

**************************************

\section{Intégrer des anticipations ancrées d'inflation à la courbe de Phillips pour le calcul de mesures du chômage d'équilibre}

L'inflation est devenue beaucoup moins sensible aux fluctuations du chômage au cours des dernières décennies. Une explication couramment avancée à cet égard, est que l'ancrage des anticipations d'inflation s'est amélioré. Ni cette explication ni l'approche économétrique retenue ne sont nouvelles, mais un des apports de ce document tient au fait que nous y utilisons deux spécifications économétriques différentes pour l'ensemble des économies de l'OCDE, celles-ci correspondant à l'« ancienne » et à la «nouvelle » spécifications employées pour calculer les mesures de l'écart de chômage sur lesquelles reposent les prévisions des Perspectives économiques de l'OCDE. L'ancienne spécification employée par l'OCDE peut être caractérisée comme une courbe de Phillips « rétrospective » classique, suivant laquelle l'inflation est expliquée en partie à l'aide d'un modèle autorégressif à retards échelonnés appliqué à l'inflation antérieure, représentant à la fois l'inertie de l'inflation et les anticipations d'inflation formées sur la base des récents résultats d'inflation. Inversement, la nouvelle approche consiste à ajuster cette spécification de manière à intégrer la notion que les anticipations d'inflation sont ancrées aux alentours de l'objectif d'inflation de la banque centrale. La principale conclusion de ce document est que la nouvelle approche donne systématiquement de meilleurs résultats que l'ancienne pour une écrasante majorité de pays de l'OCDE sur une période d'observation récente. Par rapport à la spécification rétrospective, l'approche fondée sur les anticipations ancrées tend également à mettre en évidence des écarts de chômage plus importants pour les pays où le taux de chômage effectif a le plus augmenté. En outre, la courbe de Phillips fondée sur des anticipations ancrées réduit les révisions en temps réel de l'écart de chômage, même si celles-ci restent d'une ampleur préoccupante, dans le cas des pays où le chômage a fortement varié.

Classification JEL : C22, E24, E31, J64

Mots clés : anticipations ancrées, courbe de Phillips, chômage d'équilibre, révisions en temps réel. 


\section{TABLE OF CONTENTS}

\section{INCORPORATING ANCHORED INFLATION EXPECTATIONS IN THE PHILLIPS CURVE AND IN THE DERIVATION OF OECD MEASURES OF THE UNEMPLOYMENT GAP ....................................5}

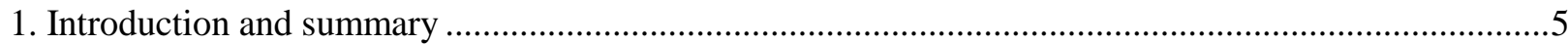

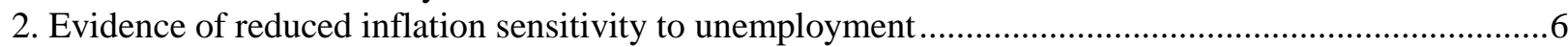

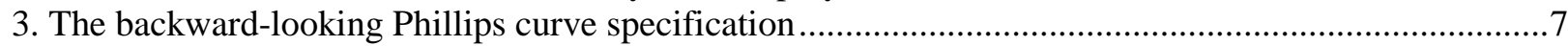

4. Evidence that long-term inflation expectations are better anchored ................................................... 8

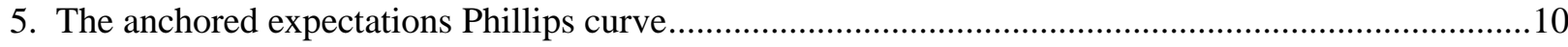

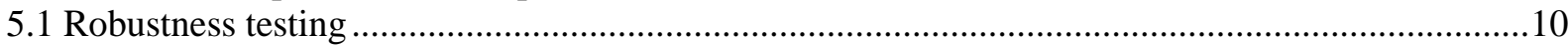

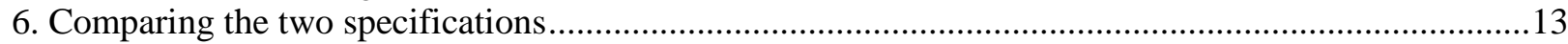

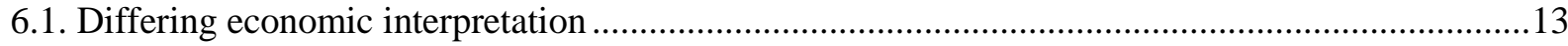

6.2. Differing estimates of the unemployment gap ….....................................................................18

7. Revisions to real-time estimates of equilibrium unemployment.........................................................19

ANNEX 1. DETAILS OF MODEL SPECIFICATIONS AND RESULTS ..............................................21

ANNEX 2. FORMAL TESTS OF THE ANCHORING OF INFLATION EXPECTATIONS ....................29

ANNEX 3. SENSITIVITY TO THE TRANSITION VARIANCE CALIBRATION ..................................30

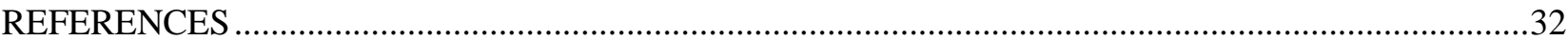

\section{Tables}

1. Significance of the unemployment gap in the backward-looking specification ............................7

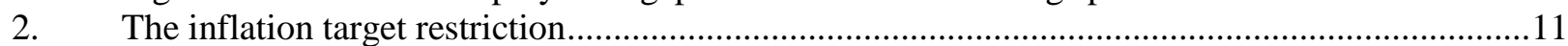

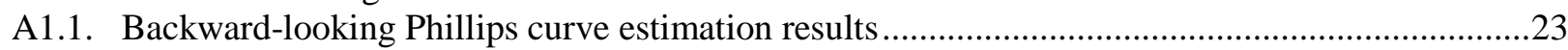

A1.2. Anchored Expectations Phillips curve estimation results …...................................................24

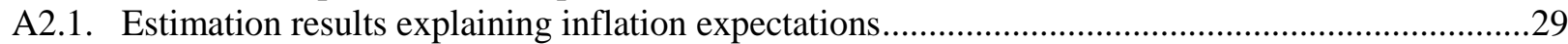

\section{Figures}

1. Inflation and unemployment in the major OECD economies over major downturns .....................6

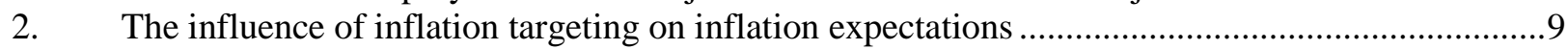

3. The estimated effect of the unemployment gap on inflation......................................................14

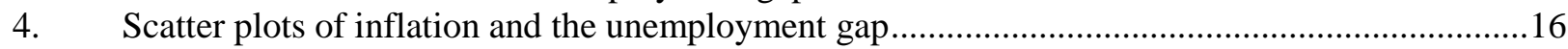

5. Equilibrium unemployment estimates for countries where unemployment increased most..........18

6. Equilibrium unemployment estimates in all other OECD countries .........................................19

7. Real-time revisions to equilibrium unemployment estimates across vintages ............................20

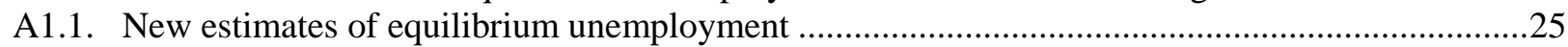

A3.1. Sensitivity tests to alternative choices of parameters in the state space equations ........................31 


\title{
INCORPORATING ANCHORED INFLATION EXPECTATIONS IN THE PHILLIPS CURVE AND IN THE DERIVATION OF OECD MEASURES OF THE UNEMPLOYMENT GAP
}

\author{
By Elena Rusticelli, David Turner and Maria Chiara Cavalleri ${ }^{1}$
}

\section{Introduction and summary}

1. The relationship between inflation and unemployment, which is at the heart of macroeconomics, has undergone a profound change over recent decades, with inflation becoming much less sensitive to movements in unemployment. A common explanation for this change is that inflation expectations have become better anchored because of credible inflation targeting by central banks. In order to evaluate this hypothesis, the paper compares two competing empirical specifications across all OECD economies, where the competing specifications correspond to the 'former' and 'new' specification for deriving measures of the unemployment gap which underlie the OECD's Economic Outlook projections. The former OECD specification can be characterised as a traditional 'backward-looking' Phillips curve, where current inflation is partly explained by an autoregressive distributed lag process of past inflation representing both inertia and inflation expectations formed on the basis of recent inflation outcomes. Conversely, the new approach adjusts this specification to incorporate the notion that inflation expectations are anchored around the central bank's inflation objective.

2. The main finding of the paper is that the anchored expectations specification systematically outperforms the 'backward-looking' specification for an overwhelming majority of OECD countries over a recent sample period. Particular emphasis is placed on the consistently higher statistical significance of the unemployment gap term in the anchored expectations specification, which implies that the corresponding unemployment gap is identified with greater confidence and precision. Conversely, the lack of statistical significance in the 'backward-looking' specification implies that the corresponding derived measure of equilibrium unemployment is little more than a filter of actual unemployment. Relatedly, the anchored expectations Phillips curve reduces real-time revisions to the unemployment gap, although these still remain uncomfortably large, in the case of countries where there have been large changes in unemployment. The difference in specifications is not just of importance in terms of statistical fit, but also in terms of the differing implied economic relationship between inflation and unemployment. This explains why the anchored expectations specification tends to imply larger unemployment gaps (or, equivalently, lower equilibrium unemployment rates) for those countries for which actual unemployment has increased the most in the aftermath of the financial crisis. This in turn may have important policy implications, if such measures are used in the measurement of structural fiscal balances or in an assessment of monetary policy requirements.

3. The next section briefly reviews the evidence that inflation has become less sensitive to movements in inflation. Section 3 describes a traditional backward-looking Phillips curve specification, which is the basis of the former OECD method for deriving the unemployment gap. Section 4 provides evidence that long-term inflation expectations have become better anchored. Section 5 describes

1. The authors are members of the Macroeconomic Analysis Division of the OECD Economics Department. They would particularly like to thank Jonathan Millar for his detailed comments and suggestions on previous empirical work, which prompted investigations into the new approach described in this paper. In addition, the authors would like to thank Werner Roeger and Douglas Sutherland for comments on the paper, the many Desk officers at the OECD who have commented on individual country results as well as Ines Gomez Palacio for assistance in preparing the document. 
amendments to the Phillips curve specification to incorporate the notion of anchored inflation expectations, as well as statistical tests of its robustness. The differing economic interpretations of the two specifications are contrasted in section 6 , together with their implications for estimates of the unemployment gap. Finally, real-time revisions to the unemployment gap before, during and after the crisis are evaluated for a selection of countries for both competing specifications in section 7 .

\section{Evidence of reduced inflation sensitivity to unemployment}

4. Given the steep and prolonged increase in unemployment in the major OECD economies in the wake of the Great Recession, the fall in core inflation has been remarkably modest. This absence of a substantial fall in inflation was recently referred to by the IMF as "the dog that didn't bark" in an allusion to a Sherlock Holmes story (IMF, 2013). It can be illustrated by the contrasting relationship between inflation and unemployment over the Great Recession for the main OECD economies with the same relationship over major downturns in the 1970s, 1980s and early 1990s (Figure 1). For the major seven OECD economies the cumulative increase in the unemployment rate from 2007 to 2014 has been more than 12 percentage point years, which has been associated with a fall in core inflation of only $1 / 3$ of a percentage point over the same period. The implied "sacrifice ratio" amounts to more than 30 , whereas it would average only about $2 \frac{1}{2} 2$ when computed over major downturns in the 1970 s, 1980 s and early 1990 s. $^{2}$

Figure 1. Inflation and unemployment in the major OECD economies over major downturns

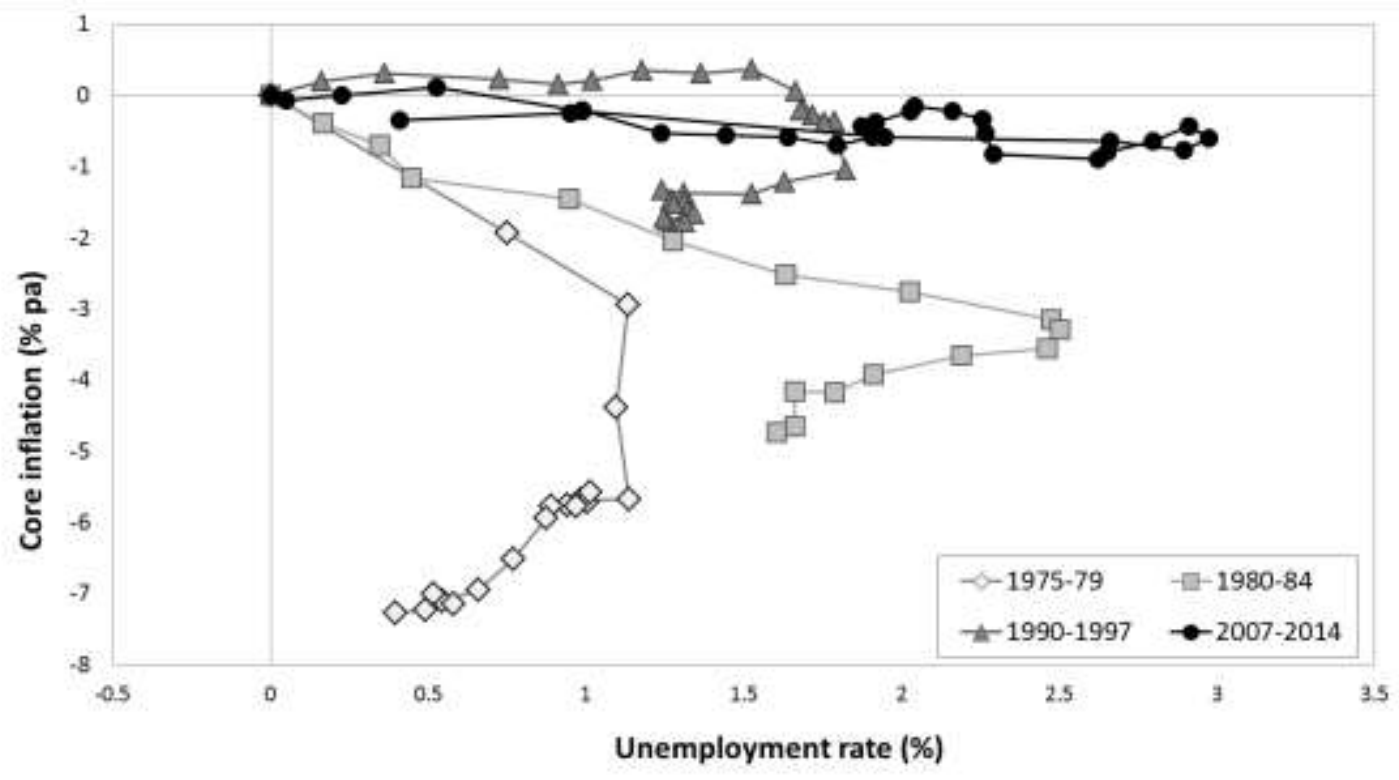

Note: the chart shows a weighted average of the change in core CPI inflation and the change in actual unemployment for the G7 countries observed each quarter from the beginning of a major downturn signalled by the start of a prolonged period of rising unemployment.

Source: OECD Main Economic Indicators database and OECD calculations.

2. The sacrifice ratio is here defined to be the cumulative percentage point increase in the unemployment rate (measured in percentage point years) associated with a fall in core inflation of one percentage pointThe calculation of sacrifice ratios in this way does not allow for a clean comparison because other factors, such as supply shocks, may also impinge on the relationship between inflation and unemployment. Nevertheless, the magnitude of the difference is so large as to be indicative of a change in the underlying relationship between inflation and unemployment. 


\section{The backward-looking Phillips curve specification}

5. The former OECD approach to estimating the Phillips curve and deriving the unemployment gap adopted a traditional backward-looking Phillips curve specification (Gianella et al., 2008; and more recently Guichard and Rusticelli, 2011). This specification, caste into a state space framework, can be summarised in terms of the description by Gordon (1997) of a 'triangle model', with the change in inflation explained in terms of three factors: demand variables, here represented by the unemployment gap; supply shock variables which have a temporary effect on inflation, represented by real import price inflation, real oil price inflation and changes in indirect taxes; and inertia represented by an autoregressive distributed lag of changes in past inflation rates:

$$
\Delta \pi_{t}=\alpha(L) \Delta \pi_{t-1}-\beta\left(U_{t}-N A I R U_{t}\right)+\text { supply shocks }+\varepsilon_{t}
$$

6. Wherever possible, inflation is specified in terms of core CPI inflation (excluding food and energy components of the CPI) in order to try to purge the dependent variable from the direct impact of some of the main supply shocks. As the unemployment gap, namely the difference between unemployment and the NAIRU (the Non-Accelerating Inflation Rate of Unemployment), is unobservable, the system is completed with two equations modelling the movements in both the NAIRU and the unemployment gap, specifically as a random walk process the first and as a second order autoregressive process for the second (see Annex 1 for details).

7. A major problem with this backward-looking specification is that when estimated over a recent sample period beginning in 1998 (see Table A1.1 in Annex 1 for details), the coefficient on the unemployment gap $(\beta)$ is not statistically significant for most OECD countries (Table 1). This so-called "flattening of the Phillips curve", where the coefficient on the unemployment gap $\beta$ is small and insignificant, is another representation of the reduced sensitivity of inflation to unemployment previously illustrated in Figure 1, and calls into question the reliability and usefulness of the Phillips curve as an appropriate empirical framework to estimate the NAIRU.

Table 1. Significance of the unemployment gap in the backward-looking specification

\begin{tabular}{|l|c|c|}
\hline Country & $1970-2014$ & 1998-2014 \\
\hline Australia & $* * *$ & $* *$ \\
Austria & $*$ & \\
Belgium & $* * *$ & \\
Canada & $* * *$ & \\
Chile & - & $* *$ \\
Colombia & $*$ & \\
Czech Republic & $* *$ & $*$ \\
Denmark & $* *$ & \\
Estonia & $* * *$ & \\
Finland & $* * *$ & \\
France & $*$ & \\
Germany & $*$ & \\
Greece & $* * *$ & $* * *$ \\
Hungary & $*$ & \\
Iceland & $* *$ & \\
Ireland & & \\
Israel & \\
Italy &
\end{tabular}

\begin{tabular}{|l|c|c|}
\hline Country & 1970-2014 & 1998-2014 \\
\hline Japan & $* * *$ & \\
Korea & $* *$ & \\
Latvia & - & \\
Luxembourg & $* * *$ & \\
Mexico & $*$ & $*$ \\
Netherlands & $* *$ & \\
New Zealand & $*$ & \\
Norway & $*$ & \\
Poland & $* * *$ & \\
Portugal & $* * *$ & \\
Slovak Republic & $*$ & \\
Slovenia & $* * *$ & \\
Spain & $* *$ & \\
Sweden & $* *$ & \\
Switzerland & $* * *$ & \\
Turkey & $* *$ & \\
United Kingdom & \\
United States & & \\
\hline
\end{tabular}

Note: ${ }^{*},{ }^{* *},{ }^{* * *}$ indicate statistical significant at $10 \%, 5 \%$ and $1 \%$ level respectively.

Source: OECD calculations. 
8. An attempt to strengthen the link between inflation and labour market dynamics considered the presence of hysteresis effects by allowing the NAIRU to change more rapidly in the presence of persistent changes in unemployment. The inclusion of long-term unemployment, chosen as a proxy of hysteresis risks and included in the state equation driving the NAIRU, helps to improve both the size and the significance of the coefficient on the unemployment gap in the estimated backward-looking Phillips curve for some countries (Rusticelli, 2014). However, this methodological modification does not perform well across all OECD countries, but rather only in the case of the European peripheral countries, where the rise in aggregate unemployment following the financial crisis was the largest. Moreover, the additional estimated parameters associated with the introduction of long-term unemployment makes the modelling framework less robust.

\section{Evidence that long-term inflation expectations are better anchored}

9. Long-term inflation expectations have become better anchored as central banks have become more explicit about their inflation objectives, often adopting specific targets for inflation. The Reserve Bank of New Zealand was the first OECD central bank to adopt a specific target for inflation in 1990, followed by the Bank of Canada in 1991. Since then, the central banks in almost all OECD countries have adopted some form of explicit objective for inflation. The European Central Bank has adopted an inflation objective of maintaining the area-wide inflation "below, but close to, 2\%" in 1998. Although until recently there was not a specific inflation objective for the United States, the financial market's reaction to FOMC statements suggested that the markets believed the Federal Reserve had an implicit long-run inflation objective of between 1 and 3.5 percent, with a mid-point of $2.25 \%$, very close to Chairman Bernanke's suggestion of $2 \%$ as optimal long-run average inflation (Thornton, 2007; Bernanke 2004).

10. Better anchored inflation expectations have been recognised as a main explanation for more stable inflation and for the absence of significant disinflation in the aftermath of the financial crisis (IMF, 2013; ECB, 2014; Coibion and Gorodnichenko, 2015; Stevens, 2014). A credible inflation objective may attract long-term inflation expectations, so decreasing inflation persistence and therefore reducing the effectiveness of the current rate of inflation to predict the rate of inflation in the next period. This is demonstrated for the major OECD economies ${ }^{3}$ where long-run inflation expectations have become much less correlated with lagged inflation since 1998 than previously (see Figure 2) and it is confirmed by more formal tests presented in Annex 2.

3. Japan has been excluded from this sample as the introduction of a formal inflation target has occurred only very recently. 
Figure 2. The influence of inflation targeting on inflation expectations

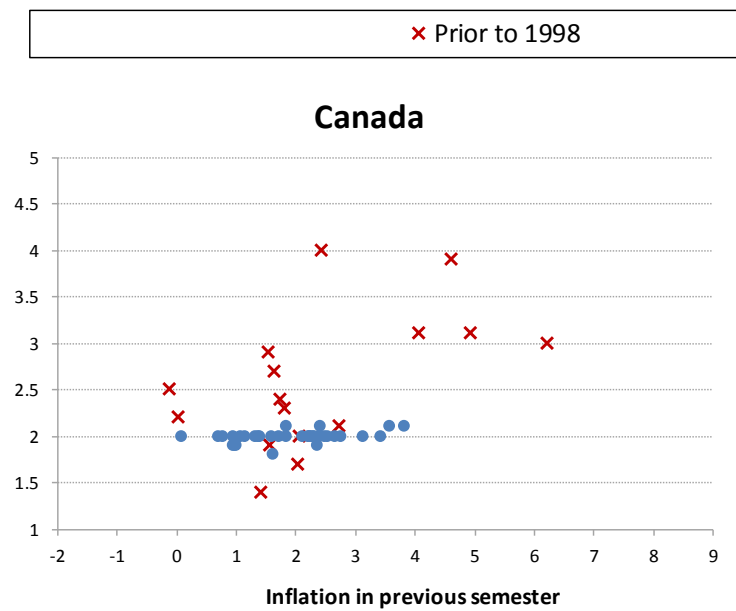

\section{Germany}
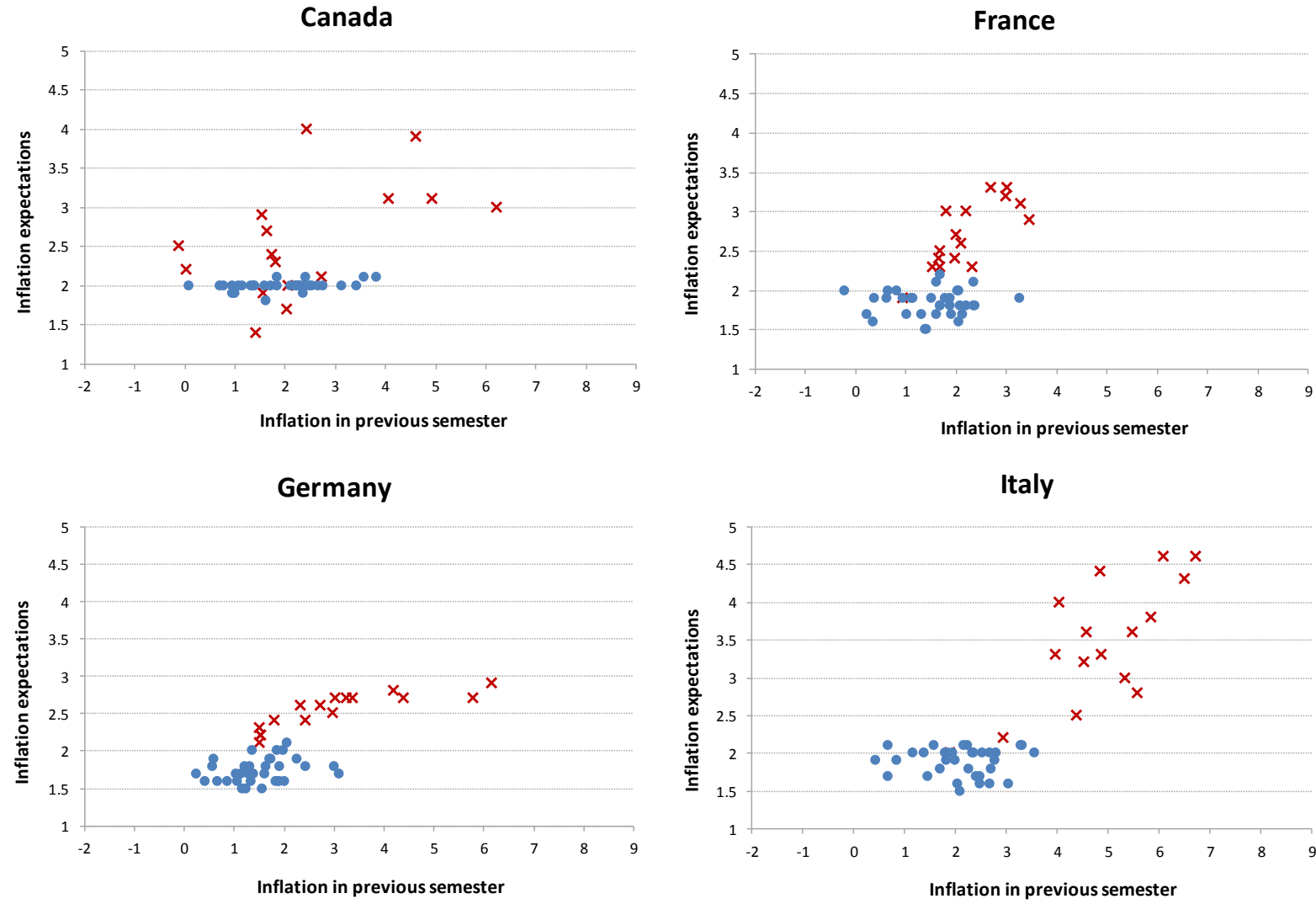

Italy

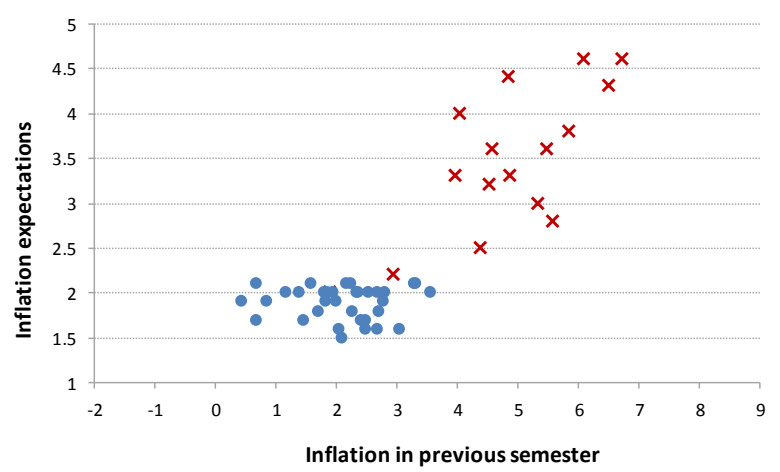

United Kingdom

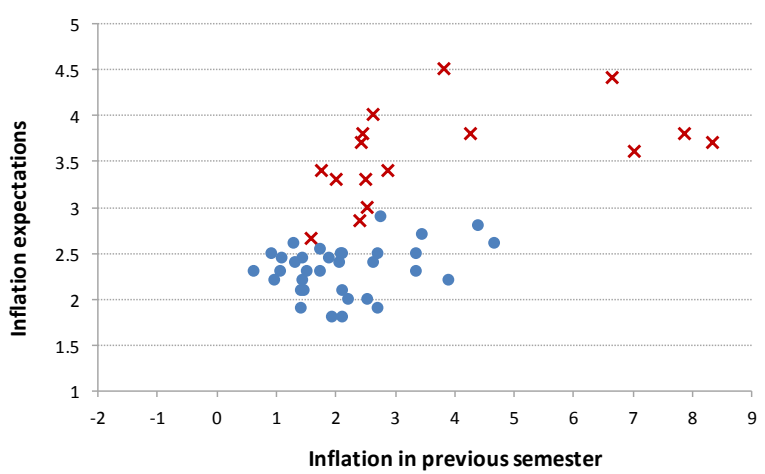

\section{United States}

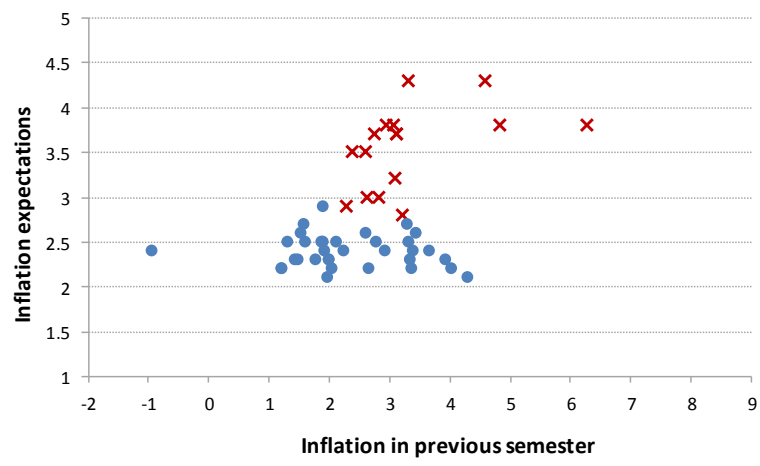

Note: Inflation expectations are the 6 to 10 years ahead expected average CPI inflation rates from the Survey of Professional Forecasters, available per semester from 1990 to 2014. Inflation is the annualised CPI inflation rate. In accordance with the start of the sample estimation period chosen for this paper, the break is chosen to be 1998.

Source: OECD calculations, OECD Main Economic Indicators database and Survey of Professional Forecasters. 


\section{The anchored expectations Phillips curve}

11. The new OECD modelling framework incorporates the notion of anchored inflation expectations in the backward-looking Phillips curve, which can be interpreted as an additional term in the deviation of lagged inflation from expected long-term inflation $\left(\pi^{e}\right)$, so that the latter acts as an attractor for inflation:

$\Delta \pi_{t}=-\theta\left(\pi_{t-1}-\pi^{e}\right)-\alpha(L) \Delta \pi_{t-1}-\beta\left(U_{t}-U_{t}^{*}\right)+$ supply shocks $+\varepsilon_{t}$

As well as this additional term, the concept of equilibrium unemployment is denoted by $\mathrm{U}^{*}$ in (2) to distinguish it from the NAIRU concept in (1), to emphasise that the economic interpretation of the two concepts is different, as described further in Section 6 below. To estimate equation (2), rather than using a survey measure, inflation expectations $\pi^{e}$ are assumed to be anchored and therefore constant over the entire estimation period, which implies the introduction of an intercept term $(\tau)$ in the specification:

$\Delta \pi_{t}=\tau-\theta \pi_{t-1}-\alpha(L) \Delta \pi_{t-1}-\beta\left(U_{t}-U_{t}^{*}\right)+$ supply shocks $+\varepsilon_{t}$

12. The alternative approach of substituting survey measures of inflation expectations in (2) could be problematic for two reasons. Firstly, there is a lack of consistent series of inflation expectations for most OECD countries over the sample period considered. Secondly, survey measures of inflation are usually defined in terms of headline CPI inflation and therefore they would be inappropriate for a Phillips curve equation specified in terms of core inflation. There is also some evidence to suggest that the second-round inflation effects of oil price changes are now relatively small (Hooker, 2002), which in turn would suggest that wage bargainers may be more focussed on an underlying or core measure of inflation and that survey measures of short-term headline inflation expectations may therefore be inappropriate in modelling the inflation process.

13. The implied level of stable inflation expectations, comparing (2) and (2a), is then given by $(\tau / \theta)$, and when there is an explicit central bank numerical objective for inflation the restriction that $(\tau / \theta)$ is equal to this objective is imposed when consistent with the data. Given the rationale underlying the new Phillips curve, the model is only estimated over a relatively recent sample period when inflation has been relatively stable and therefore inflation expectations can plausibly be considered to be anchored; hence for most countries the sample estimation period begins in 1998. For some countries, where an inflation target was introduced only recently, the restriction that inflation expectations are anchored at the target is only tested for this more recent period. For euro area countries, a restriction of $2 \%$ inflation expectations is chosen for each individual country, even though the ECB's target is for area-wide inflation to be "below, but close to, $2 \%$ over the medium term". Details on the country-specific anchored expectations Phillips curve estimates are provided in Annex 1, Table A1.2.

\subsection{Robustness testing}

14. The backward-looking Phillips curve specification (1) is a special case of the anchored expectations specification (2a), when the lagged inflation and constant terms are dropped. However, such a restriction is overwhelmingly rejected with the coefficient on lagged inflation $\theta$ being significantly different from zero for almost all countries and in $80 \%$ of the cases being statistically significant at $1 \%$ confidence level. ${ }^{4}$ The restriction that the estimated constant $(\tau)$ and the coefficient on lagged inflation $(\theta)$ are consistent with expectations being anchored at the central bank's inflation target is accepted for all countries, with the only exceptions of Japan, Latvia and Estonia (Table 2), both being countries where an explicit inflation target has only been introduced quite recently.

4. The level term of inflation is not significant in case of Colombia and Estonia, where the inflation rate has been particularly volatile over the estimation sample. 
ECO/WKP(2015)49

Table 2. The inflation target restriction

\begin{tabular}{|l|c|c|}
\hline Country & Official target (\%) & $\begin{array}{c}\text { Restriction tested \& } \\
\text { accepted (\%) }\end{array}$ \\
\hline Australia & $2-3$ & 2.5 \\
Canada & $2+/-1$ & 2 \\
Chile & $3+/-1$ & 3 \\
Colombia & $3+/-1$ & 3 \\
Czech Republic & $\begin{array}{c}3-4(2002-05) ; 3(2006-09) ; \\
2 \text { since } 2010\end{array}$ & $\begin{array}{c}\text { Time-varying, } \\
\text { according to target }\end{array}$ \\
Denmark & none & N/A \\
Euro Area & \\
Hungary & $3+2$ & 2 \\
Iceland & $2.5+/-1.5$ & 3 \\
Israel & $2+/-1$ since 2003 & 2 since 2003 \\
Japan & 2 since 2013 & not accepted \\
\hline
\end{tabular}

\begin{tabular}{|l|c|c|}
\hline Country & Official target (\%) & $\begin{array}{c}\text { Restriction tested \& } \\
\text { accepted (\%) }\end{array}$ \\
\hline Latvia & 2 since 2005 & not accepted \\
Korea & $2.5-3.5$ & 3 \\
Mexico & 3 & 3 \\
Norway & 2.5 since 2001 & 2.5 since 2001 \\
New Zealand & $0-3(1997-2002) ;$ & 2 since 2002 \\
Poland & 2.3 since 2002 & 2 since 2004 \\
Sweden & 2 & 2 \\
Switzerland & $0-2$ & 1 \\
Turkey & from 35 to 5 between $2002-$ & $\begin{array}{c}\text { Time-varying, } \\
2012 ; 5 \text { since } 2012\end{array}$ \\
according to target & 2 & 2 \\
United Kingdom & 2 since 2012 & 2 since 2012 \\
\hline United States &
\end{tabular}

Note:

1. Since 1998; unless differently indicated in the table. The official target is set on HICP inflation for euro area countries, core CPI inflation for Korea, and CPI inflation for all other countries.

2. The restriction imposed is that the intercept divided by the coefficient on lagged inflation $(\theta)$ is equal to the number in this column.

3. For the euro area, the official target is an area-wide HICP inflation close to, but below, $2 \%$. To operationalise this as a countryspecific target, a restriction of $2 \%$ was tested for each country individually from 1998, except for Latvia, Slovenia and the Slovak Republic for which the restriction was tested from 2005 and Estonia from 2011. This restriction is accepted for all countries with the exception of Estonia.

15. While the backward-looking specification yields estimates of the unemployment gap coefficient $(\beta)$ which are statistically significant to at least the $10 \%$ level for nearly all countries over a full sample (usually beginning in 1970), the coefficient is only significant in one-quarter of the cases on a shorter sample starting in 1998. Conversely, the unemployment gap is statistically significant in the expectationsaugmented Phillips curve for all countries (Table 3). Moreover, for those countries where both approaches lead to significant estimates of $\beta$, the fit of the anchored expectations Phillips curve is higher for all countries as indicated by the higher adjusted $R^{2}$. 
Significance of the unemployment gap across different Phillips curve specifications

Sample estimation period 1998-2014

\begin{tabular}{|l|c|c|}
\hline Country & $\begin{array}{c}\text { Backward- } \\
\text { looking }\end{array}$ & $\begin{array}{c}\text { Anchored } \\
\text { expectations }\end{array}$ \\
\hline Australia & $* *$ & $* *$ \\
Austria & & $* *$ \\
Belgium & & $* *$ \\
Canada & $* *$ & $* *$ \\
Chile & & $* * *$ \\
Colombia & $*$ & $* * *$ \\
Czech Republic & & $*$ \\
Denmark & & $* *$ \\
Estonia & & $*$ \\
Finland & & $*$ \\
France & & $* * *$ \\
Germany & & $* *$ \\
Greece & & $* * *$ \\
Hungary & $* * *$ & $* *$ \\
Iceland & & $*$ \\
Ireland & & \\
Israel & & \\
Italy & & \\
\hline
\end{tabular}

\begin{tabular}{|l|c|c|}
\hline Country & $\begin{array}{c}\text { Backward- } \\
\text { looking }\end{array}$ & $\begin{array}{c}\text { Anchored } \\
\text { expectations }\end{array}$ \\
\hline Japan & & $* * *$ \\
Korea & & $*$ \\
Latvia & & $* * *$ \\
Luxembourg & $*$ & $* *$ \\
Mexico & & $*$ \\
Netherlands & & $* *$ \\
New Zealand & & $*$ \\
Norway & & $*$ \\
Poland & $* *$ \\
Portugal & $* *$ \\
Slovak Republic & & $* *$ \\
Slovenia & & $* *$ \\
Spain & & $* * *$ \\
Sweden & & $* * *$ \\
Switzerland & & $* * *$ \\
Turkey & & $* *$ \\
United Kingdom & & $* *$ \\
United States & & $* *$ \\
\hline
\end{tabular}

Note: ${ }^{*},{ }^{* \star},{ }^{* \star *}$ indicate statistical significant at $10 \%, 5 \%$ and $1 \%$ level respectively.

Source: OECD calculations.

16. The higher the statistical significance of the unemployment gap term the greater the confidence one can have in the point estimate for the unemployment gap. This can be illustrated by varying the signalto-noise ratio, which controls the smoothness of the equilibrium unemployment estimates and therefore affecting the unemployment gap. If the unemployment gap in the original Phillips curve equation is highly statistically significant and a constraint on any alternative estimate of the gap is set in terms of a similar level of statistical significance, then the variation around these plausible alternative estimates of the unemployment gap is relatively small (see Annex 3 for details).

17. An alternative explanation for the reduced sensitivity of inflation to unemployment could be the presence of downward nominal wage rigidities at low levels of inflation, which implies asymmetries in the responsiveness of nominal wage growth and hence inflation to the unemployment gap (Daly et al., 2012; Yellen, 2012; Abritti and Fahr, 2013; OECD 2014). A statistical test of asymmetry was performed by testing whether the coefficient $\beta$ is statistically different when core inflation falls below 0.5 percentage points. The null hypothesis of this form of nonlinearity was rejected for more than $80 \%$ of the countries. 


\section{Comparing the two specifications}

\subsection{Differing economic interpretation}

18. The unemployment gap, derived from the two alternative Phillips curve specifications has different macroeconomic implications for inflation dynamics. In absence of any other shock, the backwardlooking specification of the Phillips curve implies that inflation will only be stable when the unemployment gap is closed (i.e. when unemployment equals the NAIRU), and it will keep falling as long as unemployment exceeds the NAIRU. In other words, a stable positive unemployment gap generates a constant rate of disinflation. Conversely, the anchored expectations specification implies that, in absence of any other shock, when the unemployment gap is closed inflation will stabilise at a level consistent with long-run inflation expectations which in most cases will be anchored at the central banks inflation objective. As a consequence, a stable and positive unemployment gap generates an inflation rate which is stable, but at a lower level than the central banks inflation objective.

19. To demonstrate these very different properties of the two specifications, the impulse response functions of annual inflation to a one percentage point increase in the unemployment gap have been evaluated according to the parameter estimates for a group of countries for which unemployment has risen most over the crisis (Figure 3). A corollary of these different properties is that a situation which is characterised by the presence of low but relatively stable core inflation will lead to very different estimates of the unemployment gap in line with to the two specifications; according to the backward-looking model the unemployment gap should be small, whereas based on the anchored expectations specification the gap could be large and relatively stable. 
Figure 3. The estimated effect of the unemployment gap on inflation

Countries where unemployment increased the most during the crisis
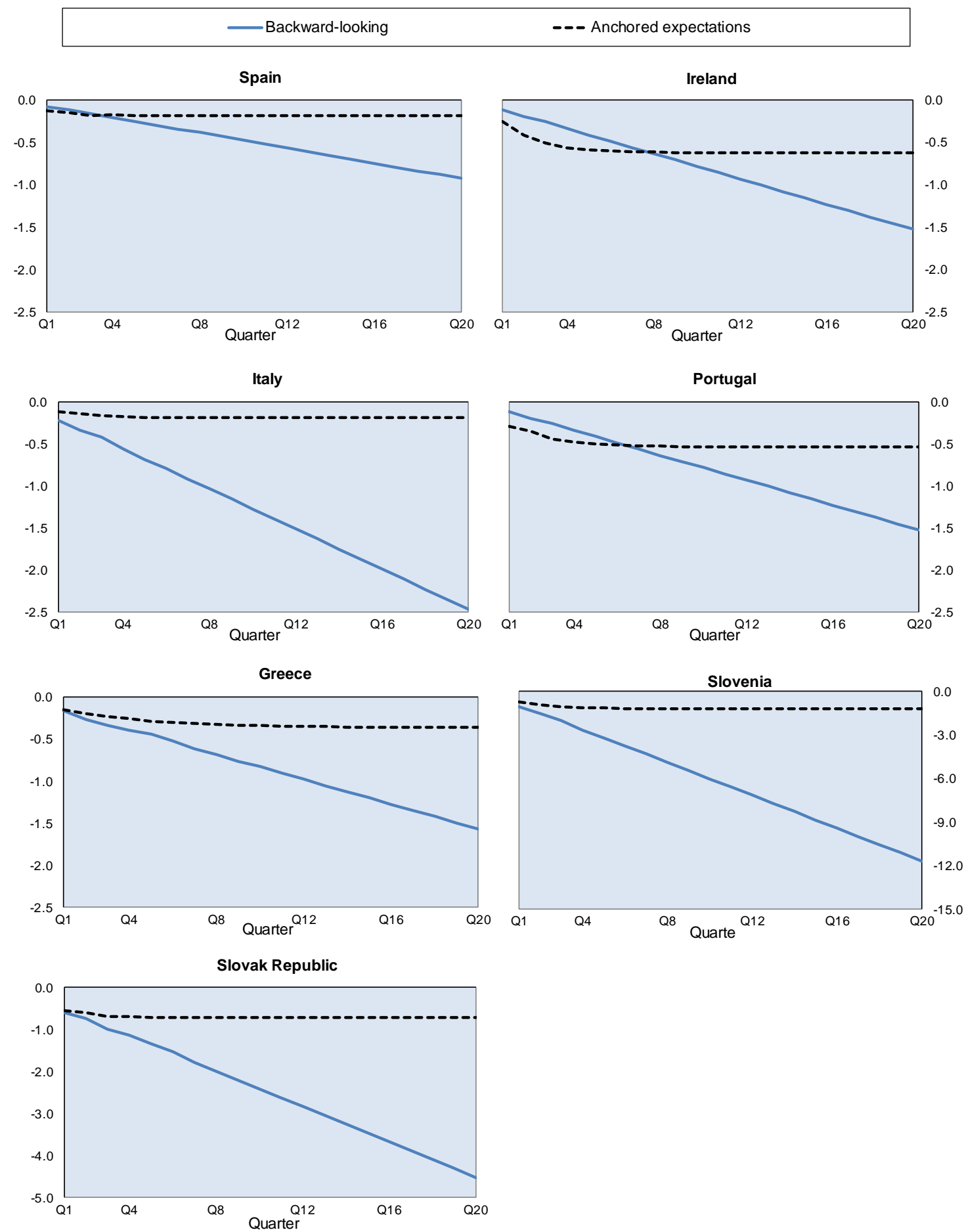

Note: The impulse response of annual inflation to a one percentage point increase in the unemployment gap, for a group of countries for which unemployment has risen most over the crisis, evaluated according to the estimated parameters of the respective models.

Source: OECD calculations. 
20. A different way of underlining both the importance of the statistical significance of the unemployment gap and the very different properties of the competing specifications, is to examine scatter plots of the relationship between core inflation and the estimated unemployment gaps, for the group of countries for which unemployment has recently increased most (Figure 4). In the backward-looking specification, the unemployment gap estimates should be correlated with the change in core inflation, while for the anchored expectations Phillips curve the gap should be correlated with the level of inflation (or more precisely the deviation of inflation from the central bank's objective). The two sets of unemployment gap estimates are obtained by applying the two different modelling frameworks and for this reason their size is different across the two Phillips curve specifications.

21. On the basis of these scatter plots, the relationship between core inflation and the unemployment gap is much clearer for the anchored expectations approach (the right-hand-side panels in Figure 4). Indeed, for most of the countries considered, the correlation between unemployment gap estimates and core inflation is statistically significant only with the anchored expectations Phillips curve. With the exception of the Slovak Republic, the anchored expectations Phillips curve performs better than the backward-looking specification for all countries. In the case of the Slovak Republic, the anchored expectations framework yields poorer estimates because core inflation was very high and relatively volatile before the recent introduction of the inflation target in 2005 .

22. While similar plots for other OECD countries tend to confirm a strong correlation between the unemployment gap and core inflation for the anchored expectations approach, there are a few exceptions. A notable exception is the United Kingdom, for which the relationship between the unemployment gap and inflation is strongly significant but has the wrong sign in the scatter plot (i.e. a positive unemployment gap is associated with higher rather than lower core inflation). The main reason behind this counter-intuitive result is due to the important role played by the supply shock variables, and in particular the large change in the exchange rate and its pass-through to inflation via import prices in the recent past. Thus, when import price and oil price inflation are properly accounted for in the in the full equation estimate of the anchored expectations Phillips curve, the estimate of the unemployment gap coefficient is both statistically significant and correctly signed, i.e. negative (Table A1.3). 
Figure 4. Scatter plots of inflation and the unemployment gap

Countries where unemployment increased the most during the crisis, 1998-2014

Backward-looking Phillips curve
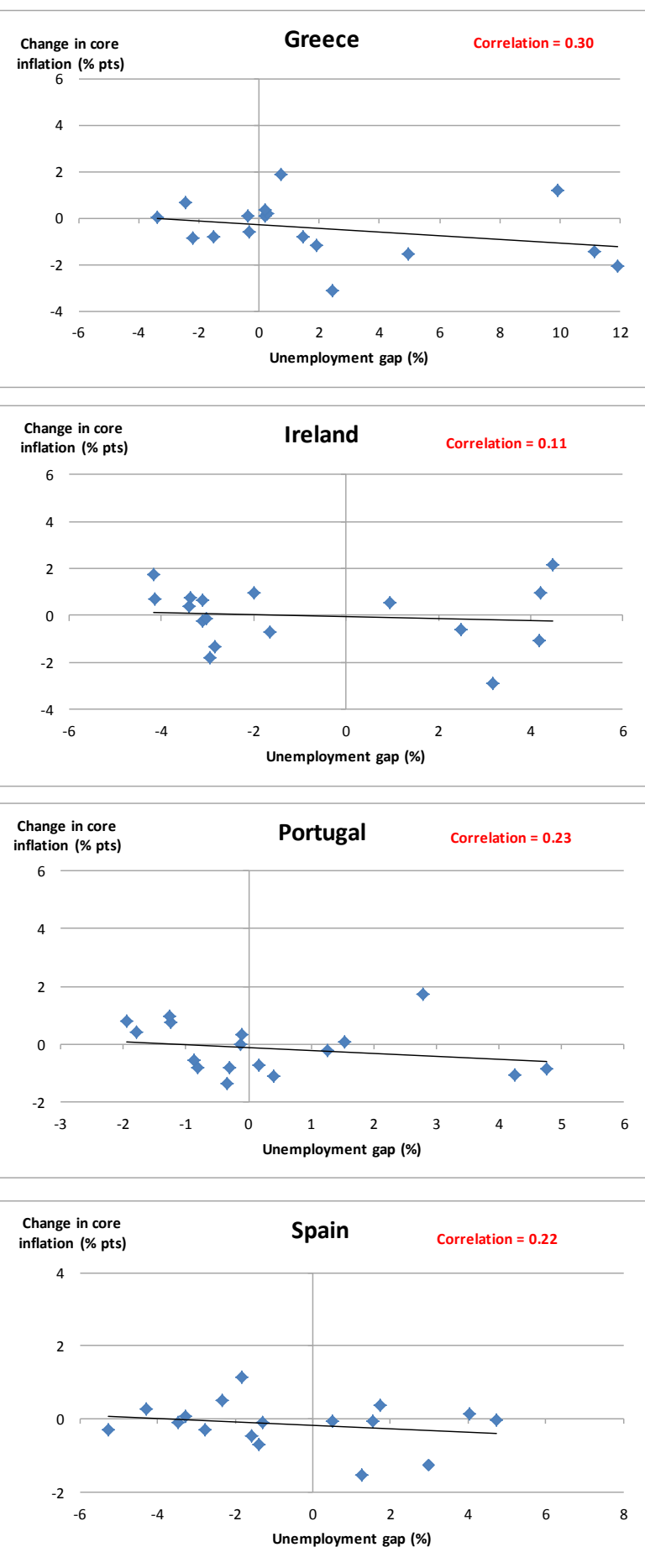

Anchored expectations Phillips curve
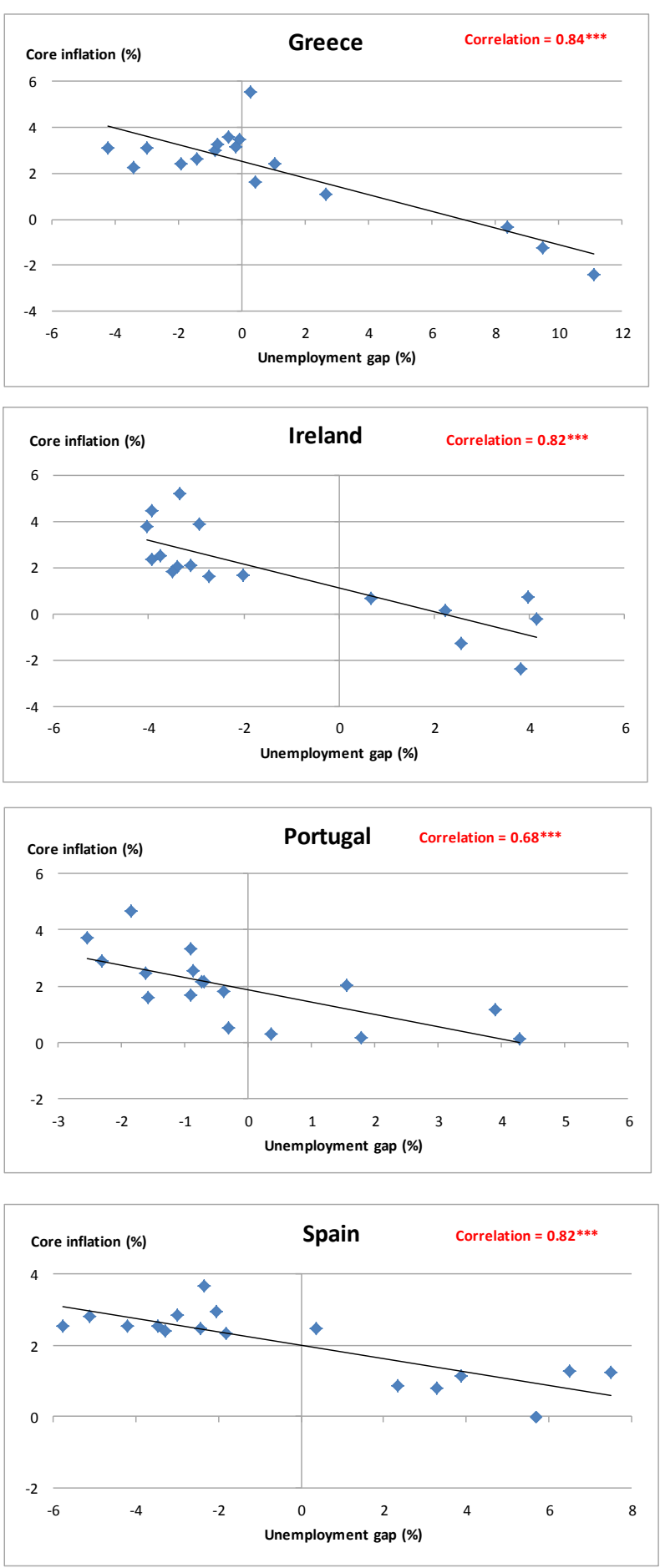
Figure 4. Scatter plots of inflation and the unemployment gap (cont'd)

Countries where unemployment increased the most during the crisis, 1998-2014

Backward-looking Phillips curve
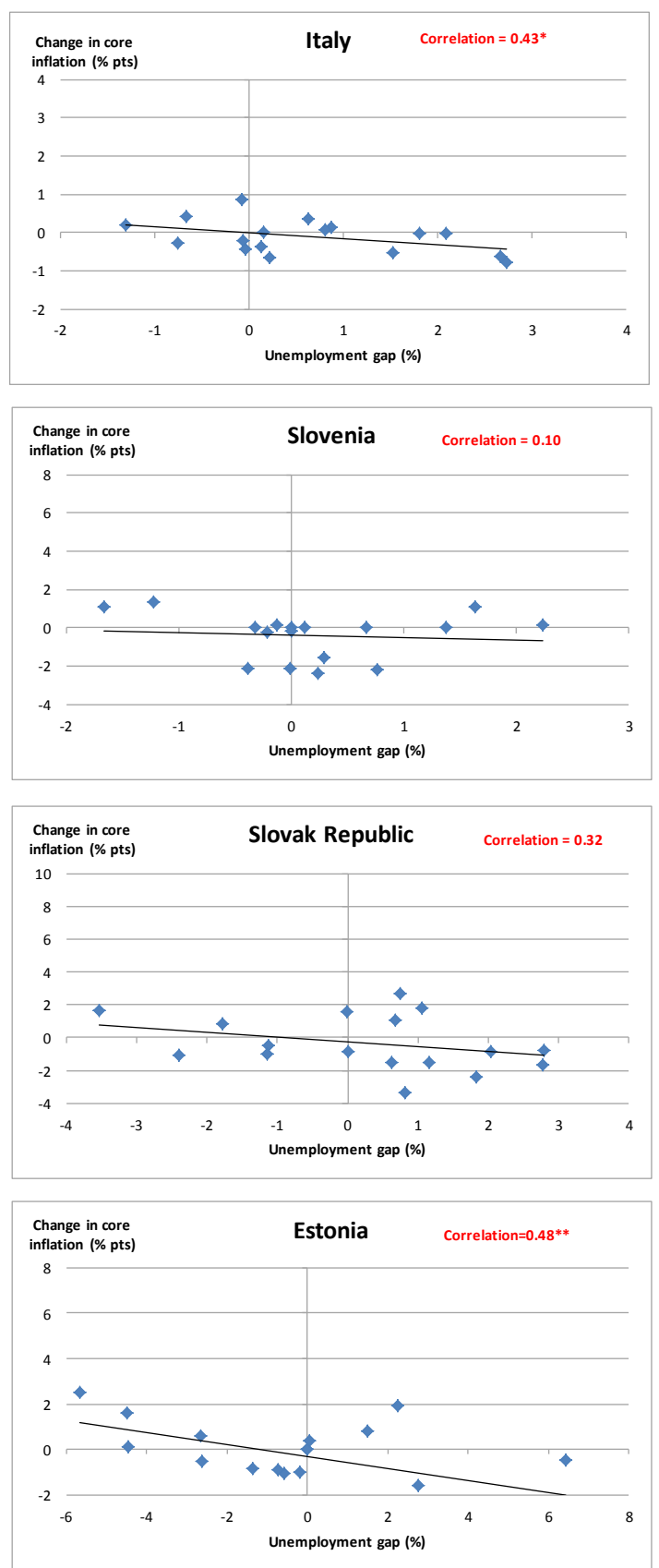

Anchored expectations Phillips curve
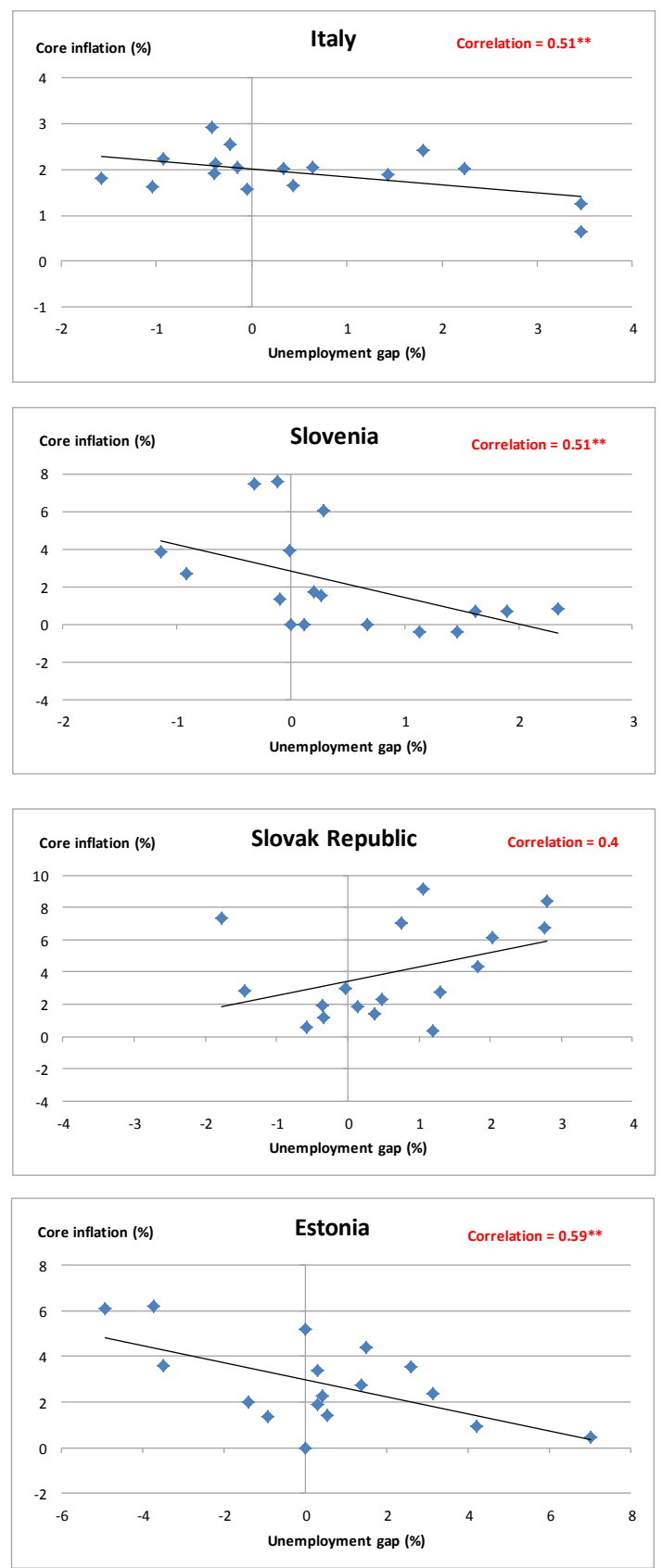

Note: Estimates of the unemployment gap are computed by applying the backward-looking Phillips curve and anchored expectations Phillips curve models, respectively. The selected countries are those where the peak rise in unemployment relative to pre-crisis levels was at least 5 percentage points.

Source: OECD Economic Outlook 96 database, OECD calculations. 


\subsection{Differing estimates of the unemployment gap}

23. The different properties of the alternative models also imply different estimates of equilibrium unemployment for some countries, particularly those for which unemployment has risen most steeply, and where typically inflation has fallen and tended to stabilise at a lower level. In these cases, the backwardlooking model will attempt to reconcile relatively stable inflation with a smaller unemployment gap, whereas the anchored expectations model will match a low level of inflation with a larger persistent unemployment gap. Thus, for the eight OECD countries where unemployment has risen the most since the crisis, the anchored expectations model implies current estimates of equilibrium unemployment which on average are nearly $2 \frac{1}{2}$ percentage points lower than the NAIRU derived from the backward-looking model (Figure 5).

24. For all other countries, for which unemployment has increased less steeply, the difference in current estimates of equilibrium unemployment is much smaller; the equilibrium unemployment estimate from the anchored expectations model is, on average, only 0.3 percentage points lower (Figure 6). In only two cases, Australia and the Netherlands, has the revised equilibrium unemployment estimate been revised upward with respect to the previous NAIRU estimate, by average 0.2 percentage points.

Figure 5. Equilibrium unemployment estimates for countries where unemployment increased most

2013 Q4

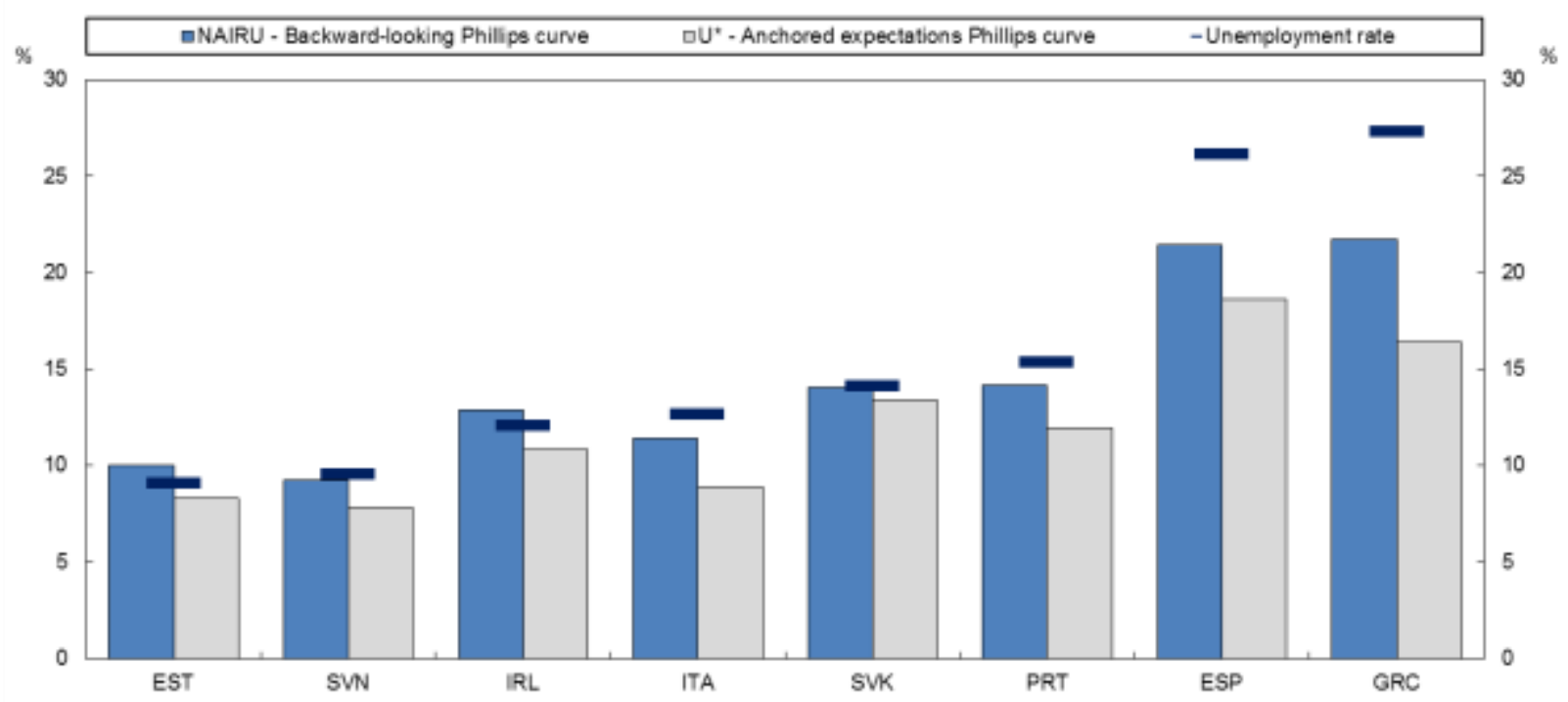

Note: Estimates of the unemployment gap for 2013Q4 for the group of OECD countries for which the peak rise in unemployment relative to pre-crisis levels was at least 5 percentage points.

Source: OECD Economic Outlook 96 database, OECD calculations. 
Figure 6. Equilibrium unemployment estimates in all other OECD countries 2013 Q4

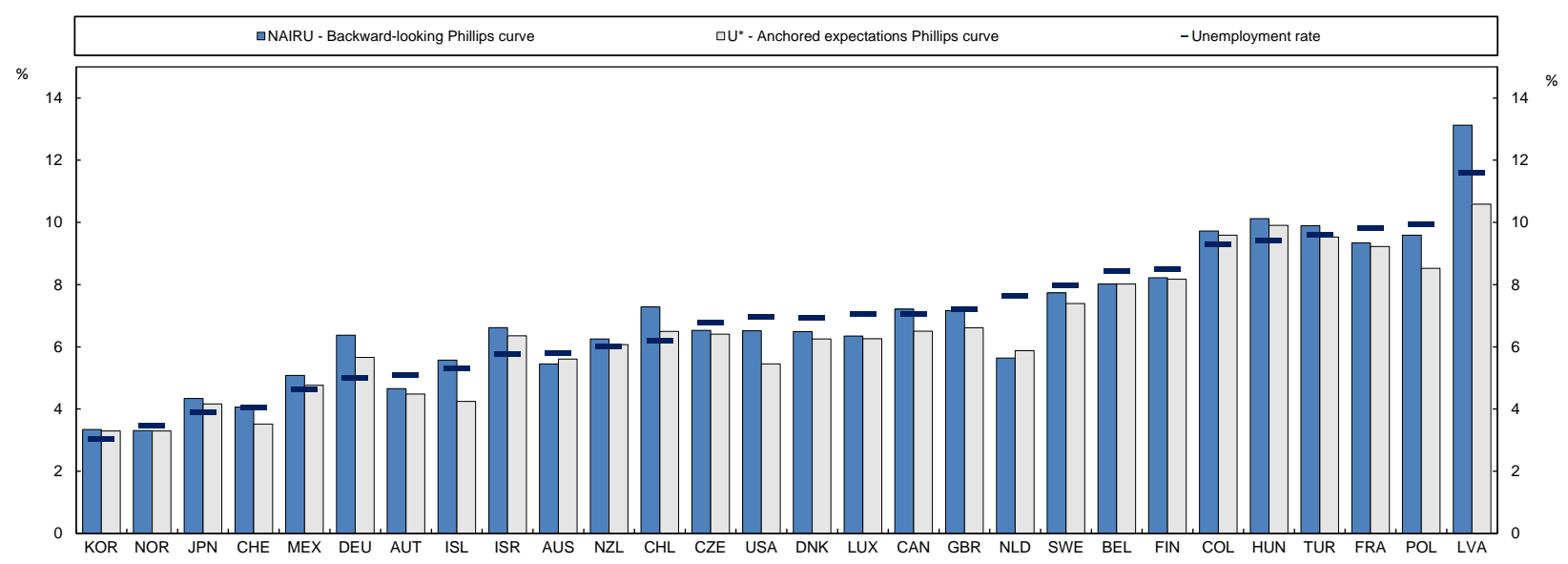

Source: OECD Economic Outlook 96 database, OECD calculations.

\section{Revisions to real-time estimates of equilibrium unemployment}

25. The robustness of the two alternative models is evaluated by comparing real-time and ex post estimates of equilibrium unemployment measures, hereafter referred to as NAIRU and U*. The set of countries considered includes those where unemployment has risen the most in the aftermath of the financial crisis. For these countries, revisions to real-time NAIRU estimates have been computed for the years 2008, 2011 and 2013, which correspond to dates when the standard OECD estimation framework has been updated to re-estimate and publish new NAIRU series. ${ }^{5}$ For the new anchored expectations approach, real-time estimates of $\mathrm{U}^{*}$ have been generated by using datasets starting in 1998 and ending in 2008, 2011 and 2013 respectively.

26. For most countries and across all updates, the revisions are generally smaller for the equilibrium unemployment estimates obtained with the anchored expectations Phillips curve, indicating a general improvement in terms of stability of the estimates (Figure 7). For Spain and Greece, where actual unemployment rose the most, the size of the revisions is the largest, however revisions to $\mathrm{U}^{*}$ are on average $1 \%$ point lower than the revisions to the NAIRU estimates. Overall, the new estimation framework yields real-time revisions which are $1 \%$ points smaller before the crisis in 2008 , and $0.35 \%$ points and $0.5 \%$ points smaller in 2011 and 2013, respectively.

27. Still, even with the anchored expectations framework, revisions to some countries for which unemployment has risen the most remain uncomfortably large (up to 3\% points for Greece and Spain). A possible reason could be linked to the choice of the autoregressive process to model the unemployment gap in the transition equation of the state space. This law of motion, imposed on the unemployment gap, ensures that the unemployment rate converges to the equilibrium rate in the absence of shocks, however it might constrain the equilibrium unemployment estimate to follow too tightly developments in the unemployment rate. Experiments with different forms of transition equations (not shown here), where the autoregressive model for the unemployment gap is dropped, tend to result in lower real-time revisions.

5. Slovenia, Slovak Republic and Estonia were excluded because the NAIRU estimation approach adopted prior to 2011 was not a backward-looking Phillips curve but an HP filter applied to the unemployment rate. 
Figure 7. Real-time revisions to equilibrium unemployment estimates across vintages

Countries where unemployment increased the most during the crisis

$\square$ Backward-looking Phillips curve
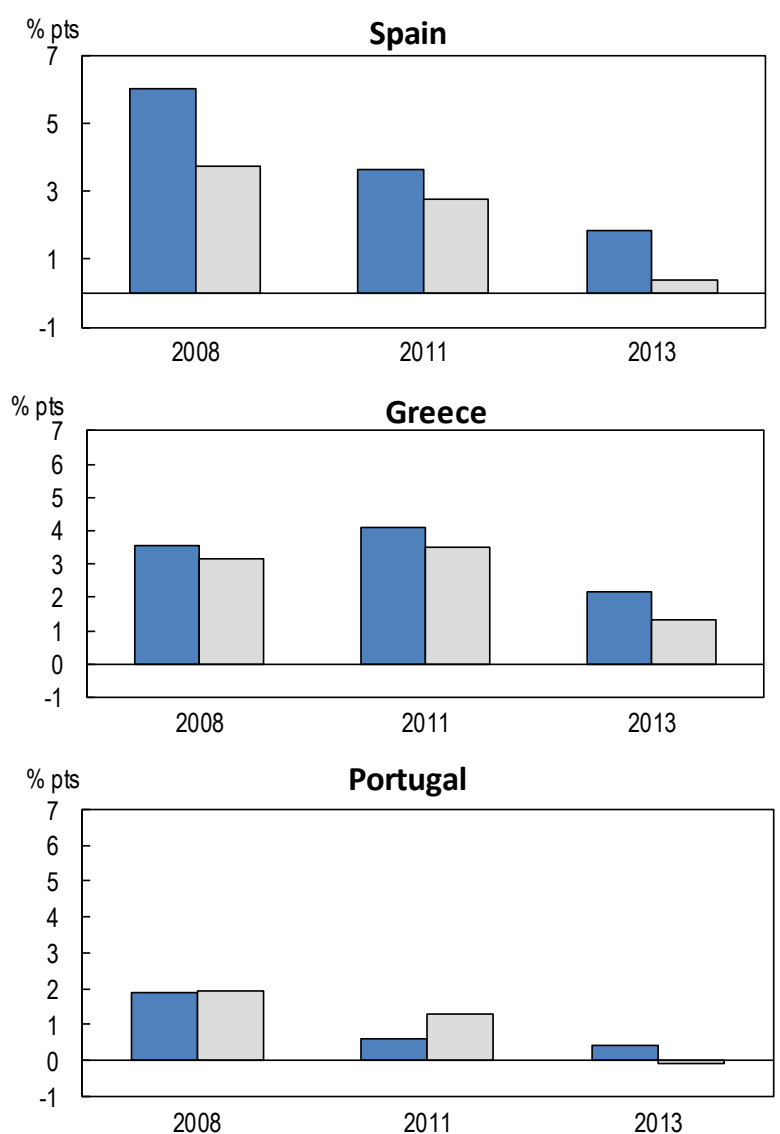

$\square$ Anchored expectations Phillips curve

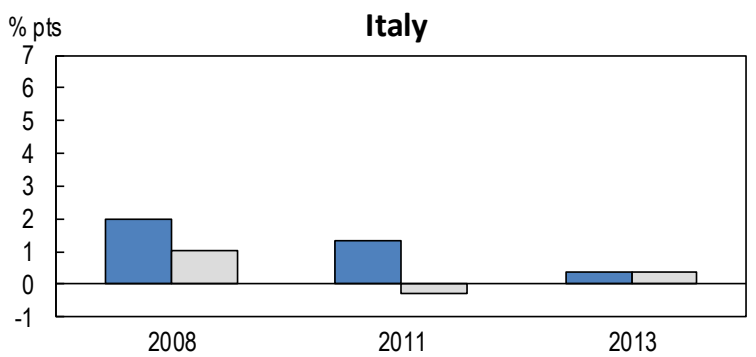

Ireland

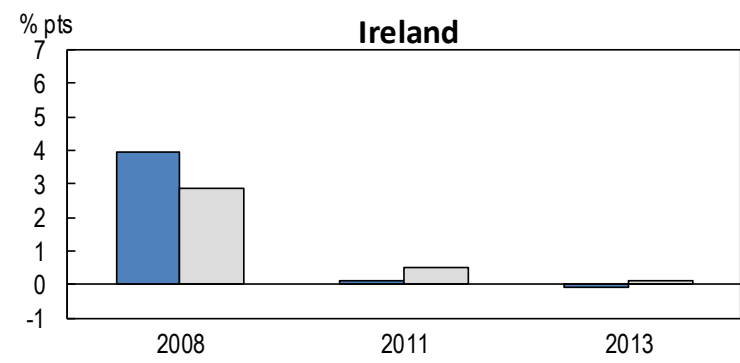

Note: Annual revisions are computed as difference between ex post and real-time equilibrium unemployment estimates for both approaches. The sample starting point considered for all estimates is 1998Q1 for the anchored expectations Phillips curve, but much earlier for the backward-looking Phillips curve. The sample ending point corresponds to the revision time, i.e. 2008Q4, 2011Q4 and 2013Q4, for the real-time estimates and to 2014Q1 for the ex post estimates.

Source: OECD calculations. 


\section{ANNEX 1. DETAILS OF MODEL SPECIFICATIONS AND RESULTS}

\section{The backward-looking Phillips curve}

The former OECD approach to estimating the unemployment gap is based on a backward-looking Phillips curve cast in a state-space framework (Gianella et al. (2008); Guichard and Rusticelli, 2011) and can be summarised as:

$$
\begin{aligned}
& \Delta \pi_{t}=\beta\left(U_{t}-U_{t}^{*}\right)+\sum_{j=1}^{A} \alpha_{j} \Delta \pi_{t-j}+\sum_{j=1}^{L} \lambda_{j} \omega_{j}^{m}\left(\pi_{t-j}^{m}-\pi_{t-j}\right)+\sum_{j=1}^{G} \gamma_{j} \omega_{j}^{o i l}\left(\pi_{t-j}^{o i l}-\pi_{t-j}\right)+ \\
& \sum_{j=1}^{D} \delta_{j} V A T_{j}+\varepsilon_{t} \\
& U_{t}=U_{t}^{*}+U_{t}^{\text {gap }} \\
& U_{t}^{\text {gap }}=\phi_{1} U_{t-1}^{g a p}+\phi_{2} U_{t-2}^{g a p}+\eta_{t} \\
& U_{t}^{*}=U_{t-1}^{*}+v_{t}
\end{aligned}
$$

The first equation represents the measurement equation of the state space model, i.e. the Phillips curve which relates changes in core consumer price inflation $\left(\Delta \pi_{\mathrm{t}}\right)$ to the unemployment gap $\left(U_{t}^{g a p}\right)$, lags of the change in inflation and control variables. ${ }^{6}$ The control variables consist of three types of short-term supply shocks: real import price inflation weighted by import penetration $\left(\omega_{j}^{m}\right)$, real oil price inflation weighted by oil intensity of production $\left(\omega_{j}^{o i l}\right)$ and indirect tax. The number of lags is determined on the basis of their statistical significance. The second equation is an identity and specifies actual unemployment $U_{t}$ as the sum of a structural component, i.e. the NAIRU $U_{t}^{*}$, and a cyclical one, i.e. the unemployment gap $U_{t}^{g a p}$.The third and fourth equations are the transition equations of the state space describing the law of motion of the two unobserved components of unemployment, where equation (1.3) specifies the unemployment gap as a stationary second-order autoregressive process (Jaeger and Parkinson, 1994; Laubach, 2001) and (1.4) specifies the NAIRU as a random walk process. ${ }^{7}$

The three error terms of the model $\varepsilon_{t}, \eta_{t}, v_{t}$ are all assumed to be i.i.d. normally distributed with mean zero and uncorrelated variances $\sigma_{\varepsilon}^{2}, \sigma_{\eta}^{2}, \sigma_{v}^{2}$, respectively. Following the approach of Staiger et al. (1997a, 1997b), Laubach (2001) and Llaudes (2005), these parameters are empirically selected on an individual country basis and fixed throughout the estimated state space model in order to preserve good distributive properties for the unobserved components. The estimation of the signal-to-noise ratio can lead to very flat NAIRUs due to the so-called pile-up problem (Stock, 1994): pure maximum likelihood estimation methods of the variance of non-stationary processes yield estimates which are downward biased towards zero when the true unknown parameter is small, as in case of the standard deviation of the innovation process in the random walk describing the NAIRU model. More details on the initialisation procedure for the state parameters and the selection of the variances of the error terms can be found in Guichard and Rusticelli (2011). Detailed estimation results for the backward-looking specification are given in Table A1.1.

6. Due to the longer span of data, headline CPI inflation is used for Canada, Greece, Portugal and the United Kingdom.

7. The sum of the autoregressive parameters is constrained to vary between 0.7 and 0.9 in order to ensure the stationarity of the unemployment gap 


\section{The anchored expectations Phillips curve}

The general specification of the model is the same as for the backward-looking Phillips curve, except for the addition of an intercept term $(\tau)$ and the lagged level of inflation. ${ }^{8}$ The restriction between the intercept and the coefficient on lagged inflation $(\theta)$ such that $\tau / \theta$ is equal to the central banks inflation objective is tested for each country. When the inflation objective is specified as a range then the mid-point of the range is taken to be the implicit target. For countries where inflation targeting has not been officially adopted, namely Japan, Latvia and Estonia, inflation expectations have not been constrained to any specific value in the Phillips curve.

Detailed estimation results for the anchored expectations specification are given in Table A1.2.

8. The Phillips curve specification for the United Kingdom contains an additional term represented by a 3 years moving average of real import price inflation. 
ECO/WKP(2015)49

Table A1.1. Backward-looking Phillips curve estimation results

\begin{tabular}{|c|c|c|c|c|c|c|c|c|c|c|c|c|c|c|}
\hline \multirow{3}{*}{ Dependent variable $\Delta \pi$} & \multicolumn{2}{|c|}{ USA } & \multicolumn{2}{|c|}{ JPN } & \multicolumn{2}{|c|}{ DEU } & \multicolumn{2}{|c|}{ FRA } & \multicolumn{2}{|c|}{ ITA } & \multicolumn{2}{|c|}{ GBR } & \multicolumn{2}{|c|}{ CAN } \\
\hline & \multicolumn{2}{|c|}{ 1998Q2-2014Q1 } & \multicolumn{2}{|c|}{ 1998Q1-2014Q1 } & \multicolumn{2}{|c|}{ 1998Q1-2014Q1 } & \multicolumn{2}{|c|}{ 1998Q1-2013Q4 } & \multicolumn{2}{|c|}{ 1998Q1-2014Q1 } & \multicolumn{2}{|c|}{ 1998Q2-2014Q1 } & \multicolumn{2}{|c|}{ 1998Q1-2014Q1 } \\
\hline & COEF & PVALUE & COEF & PVALUE & COEF & PVALUE & COEF & PVALUE & COEF & PVALUE & COEF & PVALUE & COEF & PVALUE \\
\hline Cst & & & & & & & & & & & & & & \\
\hline$\Delta \pi(-$ & -0.668 & 0.000 & -0.410 & 0.001 & -0.543 & 0.000 & -0.801 & 0.000 & -0.707 & 0.000 & -0.502 & 0.000 & -0.842 & 0.000 \\
\hline$\Delta \pi(-2)$ & -0.511 & 0.003 & -0.105 & 0.186 & -0.464 & 0.001 & -0.132 & 0.434 & -0.404 & 0.000 & -0.586 & 0.000 & -0.651 & 0.000 \\
\hline$\Delta \pi(-3)$ & -0.268 & 0.093 & & & -0.281 & 0.039 & 0.012 & 0.929 & & & -0.327 & 0.016 & -0.477 & 0.005 \\
\hline$\Delta \pi(-4)$ & $-0.28 \mathrm{C}$ & 0.035 & & & -0.245 & 0.026 & & & & & -0.370 & 0.004 & -0.283 & 0.036 \\
\hline$\Delta \pi(-5)$ & 0000 & 38 & -001 & 27 & 0012 & 0 & 0044 & 0255 & & & 45 & 50 & -001 & 0732 \\
\hline$U(-1)+U^{*}(-1)$ & -0.006 & 0.030 & -0.016 & 0.627 & -0.012 & 0.502 & -0.044 & 0.250 & -0.004 & & -0.045 & 0.450 & -0.016 & 0.135 \\
\hline$\omega^{m}(-1) *\left(\pi^{m}(-1)-\pi(-1)\right)$ & -0.022 & 0.777 & & & & & & & 0.052 & 0.249 & 0.214 & 0.050 & 0.099 & 0.036 \\
\hline 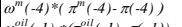 & & & & & & & & & & & -0.068 & 0.523 & 0.035 & 0.409 \\
\hline$\omega^{o i l}(-I) *\left(\pi^{i i l}(-1)-\pi(-I)\right)$ & 0.045 & 0.064 & & & -0.017 & 0.639 & 0.024 & 0.467 & & & & & 0.036 & 0.210 \\
\hline Dumn & & & & & & & & & & & & & & \\
\hline Adj R2 & & 297 & & 156 & & 261 & & 479 & & 332 & & 245 & & 338 \\
\hline
\end{tabular}

\begin{tabular}{|c|c|c|c|c|c|c|c|c|c|c|c|c|c|c|c|c|}
\hline \multirow{3}{*}{ Dependent variable $\Delta \pi$} & \multirow{2}{*}{\multicolumn{2}{|c|}{$\begin{array}{c}\text { AUS } \\
\text { 1998Q1-2014Q1 }\end{array}$}} & \multirow{2}{*}{\multicolumn{2}{|c|}{$\begin{array}{c}\text { AUT } \\
\text { 1998Q1-2013Q4 }\end{array}$}} & \multirow{2}{*}{\multicolumn{2}{|c|}{$\begin{array}{c}\text { BEL } \\
\text { 1998Q1-2014Q1 }\end{array}$}} & \multicolumn{2}{|c|}{ CHE } & \multicolumn{2}{|c|}{$\mathrm{CHL}$} & \multicolumn{2}{|c|}{$\mathrm{COL}$} & \multicolumn{2}{|c|}{ CZE } & \multicolumn{2}{|c|}{ DNK } \\
\hline & & & & & & & 1998Q1 & $-2014 Q 1$ & 1998Q1 & $-2014 Q 1$ & 2001Q1 & $-2014 Q 1$ & 2002Q1 & $-2013 \mathrm{Q} 4$ & $1998 \mathrm{Q}$ & $2013 \mathrm{Q} 4$ \\
\hline & COEF & PVALUE & COEF & PVALUE & COEF & PVALUE & COEF & PVALUE & COEF & PVALUE & COEF & PVALUE & COEF & PVALUE & COEF & PVALUE \\
\hline Cst & & & & & & & & & & & & & & & & \\
\hline $\mid \begin{array}{l}\Delta \pi(-1) \\
\Delta \pi(-2)\end{array}$ & $\begin{array}{l}-0.658 \\
-0.448\end{array}$ & $\begin{array}{l}0.000 \\
0.000\end{array}$ & $\begin{array}{l}-0.488 \\
-0.292\end{array} \mathrm{Y}$ & $\begin{array}{l}0.000 \\
0.015\end{array}$ & $\begin{array}{l}-0.385 \\
-0.236\end{array}$ & $\begin{array}{l}0.003 \\
0.074\end{array}$ & -0.577 & 0.000 & $\begin{array}{l}0.292 \\
0.186\end{array}$ & $\begin{array}{l}0.016 \\
0.142\end{array}$ & $\begin{array}{l}-0.537 \\
-0.718\end{array}$ & $\begin{array}{l}0.000 \\
0.000\end{array}$ & -0.391 & 0.005 & $\begin{array}{l}-0.637 \\
-0.233\end{array}$ & $\begin{array}{l}0.000 \\
0.072\end{array}$ \\
\hline$\Delta \pi(-3)$ & -0.250 & 0.016 & -0.320 & 0.004 & & & & & -0.123 & 0.310 & -0.485 & 0.001 & & & & \\
\hline$\Delta \pi(-4)$ & & & & & & & & & -0.412 & 0.001 & 0.173 & 0.199 & & & & \\
\hline $4 \pi(-3)$ & 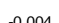 & 0981 & 0.111 & & & & -0.0077 & & 0 & 01 & 0 & & & & 00032 & \\
\hline & -0.004 & 0.981 & -0.111 & 0.044 & 0.019 & 0.821 & -0.017 & 0.738 & -0.105 & 0.121 & -0.291 & 0.038 & & 0.859 & $\begin{array}{l}-0.032 \\
0.012\end{array}$ & 0.103 \\
\hline 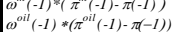 & & 0.336 & 0.186 & 0.003 & 0.031 & 0.566 & 0.060 & 0.125 & 0.212 & 0.000 & $\begin{array}{l}0.205 \\
0.145\end{array}$ & $\begin{array}{l}0.064 \\
0.031\end{array}$ & 0.064 & 0.249 & 0.012 & 0.631 \\
\hline Dummi & & OQ3 & & & & & & & & & & & & & & \\
\hline Adj R2 & & 515 & & 372 & & 098 & & 322 & & 573 & & 823 & & 145 & & 278 \\
\hline
\end{tabular}

\begin{tabular}{|c|c|c|c|c|c|c|c|c|c|c|c|c|c|c|c|c|}
\hline \multirow{3}{*}{ Dependent variable $\Delta \pi$} & \multirow{2}{*}{\multicolumn{2}{|c|}{$\begin{array}{c}\text { ESP } \\
\text { 1998Q4-2014Q1 }\end{array}$}} & \multirow{2}{*}{\multicolumn{2}{|c|}{$\begin{array}{c}\text { EST } \\
\text { 2000Q1-2013Q4 }\end{array}$}} & \multirow{2}{*}{\multicolumn{2}{|c|}{$\begin{array}{c}\text { FIN } \\
\text { 1998Q1-2013Q4 }\end{array}$}} & \multicolumn{2}{|c|}{ GRC } & \multicolumn{2}{|c|}{ HUN } & \multicolumn{2}{|c|}{ IRL } & \multicolumn{2}{|c|}{ ISL } & \multicolumn{2}{|c|}{ ISR } \\
\hline & & & & & & & 1998Q1 & -2014Q1 & 2001Q3- & $-2013 Q 4$ & $1998 \mathrm{Q}$ & $2013 Q 4$ & 1998Q1 & $-2014 Q 1$ & $1998 \mathrm{Q}$ & $-2014 Q 1$ \\
\hline & COEF & PVALUE & COEF & PVALUE & COEF & PVALUE & COEF & PVALUE & COEF & PVALUE & COEF & PVALUE & COEF & PVALUE & COEF & PVALUE \\
\hline 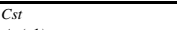 & -0.038 & 0.309 & & & & & & & & & & & & & & \\
\hline$\Delta \pi(-1)$ & -0.866 & 0.000 & -0.456 & 0.000 & -0.341 & 0.013 & -0.559 & 0.000 & -0.299 & 0.024 & -0.208 & 0.039 & -0.480 & 0.000 & -0.549 & 0.000 \\
\hline$\Delta \pi(-2)$ & -0.198 & 0.119 & & & -0.264 & 0.050 & -0.274 & 0.070 & & & -0.197 & 0.045 & & & -0.321 & 0.010 \\
\hline$\Delta \pi(-3)$ & & & & & -0.185 & 0.169 & -0.134 & 0.374 & & & 0.059 & 0.599 & & & & \\
\hline$\Delta \pi(-4)$ & & & & & & & -0.145 & 0.278 & & & & & -0.157 & 0.136 & & \\
\hline $\begin{array}{l}\Delta \pi(-5) \\
U-U^{*}\end{array}$ & -0.008 & 0.515 & -0.007 & 0.582 & 0.001 & 0.990 & -0.019 & 0.260 & -0.169 & 0.356 & -0.013 & 0.418 & -0.224 & 0.001 & -0277 & 0084 \\
\hline$\omega^{m}(-1) *\left(\pi^{m}(-1)-\pi(-1)\right)$ & & 0.515 & 0.163 & 0.000 & 0.132 & 0.040 & & 0.200 & 0.097 & 0.006 & 0.142 & 0.015 & 0.161 & 0.000 & -0.277 & 0.084 \\
\hline 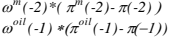 & & 0.037 & 0.103 & & & & & & & & & & & & & \\
\hline Dummies & & & & & & & & & & & $2009 \mathrm{Q1}$ & $2009 \mathrm{Q} 4$ & & & & $9 \mathrm{Q} 1$ \\
\hline Adj R2 & & 528 & & 420 & & 884 & & 193 & 0.2 & 215 & & 448 & & 383 & & 216 \\
\hline
\end{tabular}

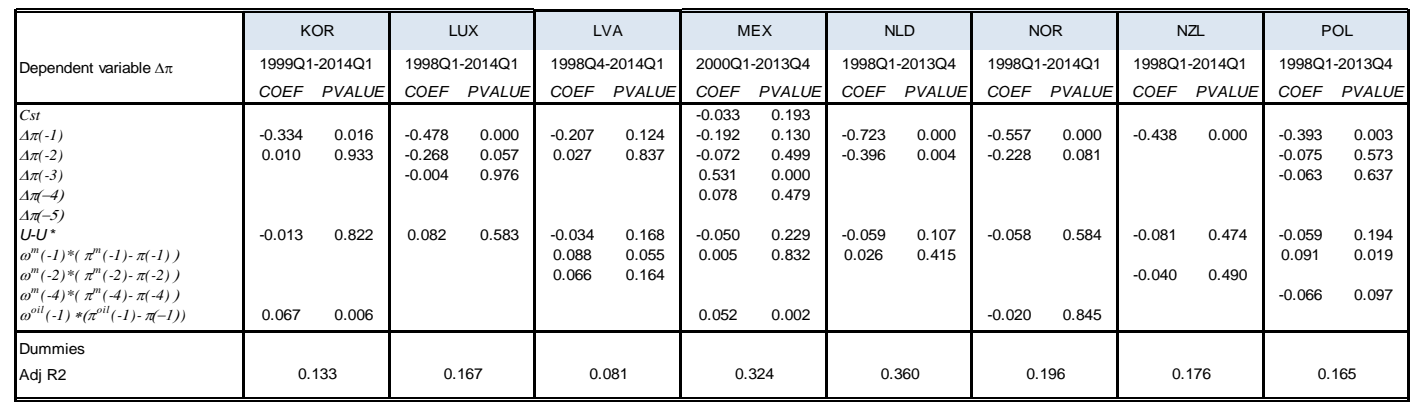

\begin{tabular}{|c|c|c|c|c|c|c|c|c|c|c|}
\hline \multirow{3}{*}{ Dependent variable $\Delta \pi$} & \multicolumn{2}{|c|}{ PRT } & \multicolumn{2}{|c|}{ svk } & \multicolumn{2}{|c|}{ SVN } & \multicolumn{2}{|c|}{ SWE } & \multicolumn{2}{|c|}{ TUR } \\
\hline & \multicolumn{2}{|c|}{ 1998Q1-2013Q4 } & \multicolumn{2}{|c|}{ 1998Q1-2014Q1 } & \multicolumn{2}{|c|}{ 1999Q1-2013Q4 } & \multicolumn{2}{|c|}{ 1998Q1-2014Q1 } & \multicolumn{2}{|c|}{ 2004Q1-2013Q4 } \\
\hline & COEF & PVALUE & COEF & PVALUE & COEF & PVALUE & COEF & PVALUE & COEF & PVALUE \\
\hline \begin{tabular}{|l} 
Cst \\
\end{tabular} & & & -0.220 & 0.014 & & & & & 0.533 & 0.542 \\
\hline$\Delta \pi(-1)$ & -0.530 & 0.000 & -0.740 & 0.000 & -0.431 & 0.000 & -0.761 & 0.000 & -0.407 & 0.049 \\
\hline$\Delta \pi(-2)$ & -0.416 & 0.003 & -0.383 & 0.000 & & & -0.429 & 0.001 & -0.013 & 0.945 \\
\hline$\Delta \pi(-3)$ & & & -0.379 & 0.000 & & & & & & \\
\hline$\Delta \pi(-4)$ & & & -0.298 & 0.003 & & & & & & \\
\hline$\Delta \pi(-5)$ & & & -0.166 & 0.046 & & & & & & \\
\hline & -0.027 & 0.394 & -0.133 & 0.012 & -0.097 & 0.145 & -0.058 & 0.254 & -0.107 & 0.378 \\
\hline$\omega^{m}(-1)^{*}\left(\pi^{m}(-1)-\pi(-1)\right.$ & 0.203 & 0.047 & & & & & 0.092 & 0.379 & 0.080 & 0.461 \\
\hline Dummies & \multirow{2}{*}{\multicolumn{2}{|c|}{0.211}} & \multirow{2}{*}{\multicolumn{2}{|c|}{$\begin{array}{c}\text { 1999Q3, 2003Q1 } \\
0.758\end{array}$}} & \multirow{2}{*}{\multicolumn{2}{|c|}{$\begin{array}{c}1999 Q 3,2008 Q 4 \\
0,530\end{array}$}} & \multirow{2}{*}{\multicolumn{2}{|c|}{0.382}} & \multirow{2}{*}{\multicolumn{2}{|c|}{$\begin{array}{c}2004 \mathrm{Q} 2 \\
0.041\end{array}$}} \\
\hline Adj R2 & & & & & & & & & & \\
\hline
\end{tabular}

Source: OECD calculations. 
Table A1.2. Anchored Expectations Phillips curve estimation results

\begin{tabular}{|c|c|c|c|c|c|c|c|c|c|c|c|c|c|c|}
\hline \multirow{3}{*}{ Dependent variable $\Delta \pi$} & \multicolumn{2}{|c|}{ USA } & \multicolumn{2}{|c|}{ JPN } & \multicolumn{2}{|c|}{ DEU } & \multicolumn{2}{|c|}{ FRA } & \multicolumn{2}{|c|}{ ITA } & \multicolumn{2}{|c|}{ GBR } & \multicolumn{2}{|c|}{ CAN } \\
\hline & 1998 & -2014Q1 & $1998 \mathrm{Q}$ & 1-2014Q1 & $1998 C$ & 1-2014Q1 & $1998 Q$ & |-2013Q4 & 1998Q2 & 2-2014Q1 & $2000 c$ & 1-2014Q1 & 19950 & 3-2014Q1 \\
\hline & COEF & PVALUE & COEF & PVALUE & COEF & PVALUE & COEF & PVALUE & COEF & PVALUE & COEF & PVALUE & COEF & PVALUE \\
\hline Cst & 0.235 & 0.003 & -0.024 & 0.385 & & & & & & & & & & \\
\hline$\Delta \pi(-1)$ & -0.84 & 0.000 & & & -0.539 & 0.000 & -0.869 & 0.000 & -0.876 & 0.000 & -0.843 & 0.000 & -0.805 & 0.000 \\
\hline$\Delta \pi(-2)$ & -0.74 & 0.000 & & & -0.473 & 0.001 & -0.278 & 0.057 & & & -0.786 & 0.000 & & \\
\hline$\Delta \pi(-3)$ & -0.54 & 0.002 & & & -0.313 & 0.023 & & & & & -0.782 & 0.000 & & \\
\hline$\Delta \pi(-4)$ & & & & & & & & & & & -0.753 & 0.000 & & \\
\hline$\pi(*)$ & -0.54 & 0.002 & -0.870 & 0.000 & -0.223 & 0.032 & -0.175 & 0.061 & -0.637 & 0.000 & -0.491 & 0.008 & -0.780 & 0.000 \\
\hline & & & -0.124 & 0.004 & -0.042 & 0.088 & -0.054 & & & & & & & \\
\hline $\mid \begin{array}{l}U(-1)+U^{*}(-1) \\
U(-2)+U^{*}(-2)\end{array}$ & -0.018 & 0.044 & & & & & & & -0.030 & 0.055 & -0.072 & 0.092 & -0.050 & 0.036 \\
\hline$\omega^{\omega^{m} *(}\left(\pi^{m}-\pi\right)$ & 0.179 & 0.000 & & & & & & & & & & & & \\
\hline 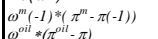 & & & & & 0.098 & 0.031 & & & 0.060 & 0.146 & 0154 & 0.073 & 0.058 & 0.066 \\
\hline Dummies & & & & & & & & & & & & /AT & & \\
\hline Adj R2 & & 460 & & 463 & & 304 & & 510 & & 422 & & .772 & & 441 \\
\hline
\end{tabular}

\begin{tabular}{|c|c|c|c|c|c|c|c|c|c|c|c|c|c|c|c|c|}
\hline \multirow{3}{*}{ Dependent variable $\Delta \pi$} & \multicolumn{2}{|c|}{ AUS } & \multicolumn{2}{|c|}{ AUT } & \multicolumn{2}{|c|}{ BEL } & \multicolumn{2}{|c|}{ CHE } & \multicolumn{2}{|c|}{$\mathrm{CHL}$} & \multicolumn{2}{|c|}{$\mathrm{COL}$} & \multicolumn{2}{|c|}{ CZE } & \multicolumn{2}{|c|}{ DNK } \\
\hline & \multicolumn{2}{|c|}{ 1998Q1-2014Q1 } & \multicolumn{2}{|c|}{ 1998Q1-2013Q4 } & \multicolumn{2}{|c|}{ 1998Q3-2014Q1 } & \multicolumn{2}{|c|}{ 1996Q1-2014Q1 } & \multicolumn{2}{|c|}{ 2000Q3-2014Q1 } & \multicolumn{2}{|c|}{ 2001Q1-2014Q1 } & \multicolumn{2}{|c|}{ 1998Q1-2013Q4 } & \multicolumn{2}{|c|}{ 1998Q1-2013Q4 } \\
\hline & COEF & PVALUE & COEF & PVALUE & COEF & PVALUE & COEF & PVALUE & COEF & PVALUE & COEF & PVALUE & COEF & PVALUE & COEF & PVALUE \\
\hline Cst & & & & & & & 0.082 & 0.114 & & & & & 1.000 & 0.003 & 0.223 & 0.002 \\
\hline$\Delta \pi(-1$ & -0.959 & 0.000 & -0.642 & 0.000 & -0.813 & 0.000 & -0.778 & 0.000 & 0.558 & 0.000 & -0.697 & 0.000 & -0.819 & 0.000 & -0.760 & 0.000 \\
\hline$\Delta \pi(-2)$ & & & -0.463 & 0.003 & & & & & & & -0.958 & 0.000 & & & & \\
\hline$\Delta \pi(-3)$ & & & & & & & & & & & -0.715 & 0.000 & & & & \\
\hline$\pi(*)$ & -0.971 & 0.000 & -0.484 & 0.002 & -0.757 & 0.000 & -0.436 & 0.001 & -0.089 & 0.094 & -0.138 & 0.158 & -0.574 & 0.000 & -0.496 & 0.001 \\
\hline & -0.316 & 0.026 & -0.115 & 0.038 & -0.082 & 0.044 & -0.108 & 0.009 & -0.159 & 0.011 & -0.338 & 0.007 & -0.272 & 0.009 & -0.027 & 0.108 \\
\hline$\omega^{m}(-1)^{*}\left(\pi^{m}(-1)-\pi(-1)\right)$ & & & 0.128 & & & & 0.040 & & & & 0.241 & 0.026 & 0.096 & 0.104 & & \\
\hline $\begin{array}{l}\omega^{o \text { oil }} *\left(\pi^{\text {oil }}-\pi(-1)\right) \\
\omega^{o u}(-1) *\left(\pi^{\prime \prime \prime}(-1)-\pi(-1)\right)\end{array}$ & 0.252 & 0.001 & & & & & & & & & & & & & & \\
\hline Dummies & & 0Q3-4 & & & & & & & & 10Q1 & & & & & & \\
\hline Adj R2 & & 779 & & 376 & & 387 & & 382 & & 617 & & 829 & & 440 & & 364 \\
\hline
\end{tabular}

\begin{tabular}{|c|c|c|c|c|c|c|c|c|c|c|c|c|c|c|c|c|}
\hline \multirow{3}{*}{ Dependent variable $\Delta \pi$} & \multirow{2}{*}{\multicolumn{2}{|c|}{$\begin{array}{c}\text { ESP } \\
1998 Q 4-2014 Q 1\end{array}$}} & \multicolumn{2}{|c|}{ EST } & \multicolumn{2}{|c|}{ FIN } & \multicolumn{2}{|c|}{ GRC } & \multicolumn{2}{|c|}{ HUN } & \multicolumn{2}{|c|}{ IRL } & \multicolumn{2}{|c|}{ ISL } & \multicolumn{2}{|c|}{ ISR } \\
\hline & & & $2000 \mathrm{Q} 3$ & 3-2013Q4 & 1998Q1 & - -2013Q4 & 1998Q1 & 2014Q1 & $2001 \mathrm{Q3}$ & 3-2013Q4 & 1998Q1 & $-2013 \mathrm{Q} 4$ & 1998Q1 & $-2014 Q 2$ & $1998 \mathrm{Q}$ & 2014Q1 \\
\hline & COEF & PVALUE & COEF & PVALUE & COEF & PVALUE & COEF & PVALUE & COEF & PVALUE & COEF & PVALUE & COEF & PVALUE & COEF & PVALUE \\
\hline Cst & & & 0.443 & 0.011 & & & & & & & & & & & 0.909 & 0.001 \\
\hline$\Delta \pi(-1)$ & -0.865 & 0.000 & 0.349 & 0.011 & -0.625 & 0.000 & -0.729 & 0.000 & & & -0.332 & 0.002 & -0.693 & 0.000 & -0.945 & 0.000 \\
\hline$\Delta \pi(-2)$ & -0.581 & 0.002 & & & -0.605 & 0.000 & -0.543 & 0.002 & & & & & & & & \\
\hline$\Delta \pi(-3)$ & & & & & & & -0.533 & 0.002 & & & & & & & & \\
\hline$\pi(*)$ & -0.708 & 0.001 & -0.098 & 0.139 & -0.357 & 0.015 & -0.425 & 0.001 & -0.637 & 0.000 & -0.405 & 0.000 & -0.305 & 0.000 & -0.936 & 0.000 \\
\hline & -0.031 & 0.009 & -0.055 & 0.047 & -0.200 & 0.056 & -0.039 & 0.010 & -0.252 & 0.037 & -0.063 & 0.003 & -0.104 & 0.018 & -0.305 & 0.010 \\
\hline 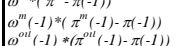 & 0.040 & 0.608 & 0.093 & 0.101 & 0.279 & 0.000 & & & 0.030 & 0.420 & 0.104 & 0.057 & 0.212 & 0.000 & & \\
\hline Dummies & & & & & & & & AT & & & & $9 \mathrm{Q} 1$ & & & & $9 \mathrm{QQ1}$ \\
\hline Adj R2 & & 459 & & 385 & & 434 & & 315 & & 357 & & 518 & & .468 & & 137 \\
\hline
\end{tabular}

\begin{tabular}{|c|c|c|c|c|c|c|c|c|c|c|c|c|c|c|c|c|}
\hline \multirow{3}{*}{ Dependent variable $\Delta \pi$} & \multirow{2}{*}{\multicolumn{2}{|c|}{$\begin{array}{c}\text { KOR } \\
\text { 1998Q4-2014Q1 }\end{array}$}} & \multirow{2}{*}{\multicolumn{2}{|c|}{\begin{tabular}{c|} 
LUX \\
1998Q3-2014Q1
\end{tabular}}} & \multirow{2}{*}{\multicolumn{2}{|c|}{$\begin{array}{c}\text { LVA } \\
1998 Q 1-2014 Q 4\end{array}$}} & \multirow{2}{*}{\multicolumn{2}{|c|}{$\begin{array}{c}\text { MEX } \\
\text { 2000Q1-2013Q4 }\end{array}$}} & \multirow{2}{*}{\multicolumn{2}{|c|}{$\begin{array}{c}\text { NLD } \\
\text { 1998Q1-2013Q4 }\end{array}$}} & \multirow{2}{*}{\multicolumn{2}{|c|}{$\begin{array}{c}\text { NOR } \\
\text { 1998Q1-2014Q1 }\end{array}$}} & \multirow{2}{*}{\multicolumn{2}{|c|}{$\begin{array}{c}\text { NZL } \\
\text { 1998Q1-2014Q1 }\end{array}$}} & \multicolumn{2}{|c|}{ POL } \\
\hline & & & & & & & & & & & & & & & $1998 C$ & $2013 \mathrm{Q} 4$ \\
\hline & COEF & PVALUE & COEF & PVALUE & COEF & PVALUE & COEF & PVALUE & COEF & PVALUE & COEF & PVALUE & COEF & PVALUE & COEF & PVALUE \\
\hline \begin{tabular}{|l|}
$s t$ \\
$\Delta \pi(-1)$ \\
$\Delta \pi(-2)$ \\
$\Delta \pi(-3)$
\end{tabular} & -0.521 & 0.000 & -0.874 & 0.000 & $\begin{array}{l}0.335 \\
-0.443\end{array}$ & $\begin{array}{l}0.000 \\
0.000\end{array}$ & $\begin{array}{l}-0.424 \\
-0.420\end{array}$ & $\begin{array}{l}0.001 \\
0.001\end{array}$ & -0.807 & 0.000 & $\begin{array}{l}0.222 \\
-0.714\end{array}$ & \begin{tabular}{l|}
0.086 \\
0.000
\end{tabular} & 0.363 & 0.001 & $\begin{array}{l}0.241 \\
-0.499 \\
-0.257\end{array}$ & $\begin{array}{l}0.269 \\
0.000 \\
0.067\end{array}$ \\
\hline$\pi(*)$ & -0.317 & 0.005 & -0.711 & 0.000 & -0.465 & 0.000 & -0.235 & 0.000 & -0.628 & 0.000 & -0.521 & 0.001 & -0.934 & 0.000 & -0.185 & 0.038 \\
\hline $\mid \begin{array}{l}U-U^{*} \\
\omega^{m * *}\left(\pi^{m}-\pi(-1)\right)\end{array}$ & -0.081 & 0.102 & -0.227 & 0.031 & -0.096 & 0.000 & -0.062 & 0.109 & -0.078 & 0.026 & -0.188 & 0.058 & -0.202 & 0.020 & -0.035 & 0.091 \\
\hline 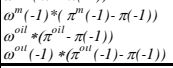 & 0.053 & 0.017 & $\begin{array}{l}0.016 \\
0.243\end{array}$ & $\begin{array}{l}0.113 \\
0.000\end{array}$ & & & 0.035 & 0.011 & & & & & & & 0.074 & 0.048 \\
\hline Dummies & & & & & 200 & $9 \mathrm{Q} 2$ & & & & & & & & & & \\
\hline Adj R2 & & 250 & & 640 & 0.5 & 39 & & .429 & & 394 & & 309 & & 461 & & 229 \\
\hline
\end{tabular}

\begin{tabular}{|c|c|c|c|c|c|c|c|c|c|c|}
\hline \multirow{3}{*}{ Dependent variable $\Delta \pi$} & \multicolumn{2}{|c|}{ PRT } & \multicolumn{2}{|c|}{ sVk } & \multicolumn{2}{|c|}{ SVN } & \multicolumn{2}{|c|}{ SWE } & \multicolumn{2}{|c|}{ TUR } \\
\hline & \multicolumn{2}{|c|}{ 1998Q1-2013Q4 } & \multicolumn{2}{|c|}{ 1998Q1-2014Q2 } & \multicolumn{2}{|c|}{ 1998Q1-2013Q4 } & \multicolumn{2}{|c|}{ 1998Q1-2014Q1 } & \multicolumn{2}{|c|}{ 1998Q1-2013Q4 } \\
\hline & COEF & PVALUE & COEF & PVALUE & COEF & PVALUE & COEF & PVALUE & COEF & PVALUE \\
\hline \begin{tabular}{|l} 
Cst \\
\end{tabular} & & & 2.173 & 0.000 & 0.824 & 0.020 & & & -0.654 & 0.001 \\
\hline$\Delta \pi(-1)$ & -0.807 & 0.000 & -0.893 & 0.000 & -0.751 & 0.000 & -0.998 & 0.000 & -0.763 & 0.000 \\
\hline$\Delta \pi(-2)$ & & & & & -0.638 & 0.003 & & & & \\
\hline$\pi(*)$ & -0.551 & 0.000 & -0.751 & 0.000 & -0.629 & 0.005 & -0.920 & 0.000 & -0.544 & 0.000 \\
\hline$u-u^{*}$ & -0.074 & 0.002 & -0.137 & 0.038 & -0.188 & 0.017 & -0.164 & 0.002 & -0.506 & 0.047 \\
\hline$\omega_{m}^{m}(-1)^{*}$ & 0.111 & 0.059 & & & & & 0.207 & 0.018 & 0.549 & 0.036 \\
\hline$\omega^{m}(-1) *\left(\pi^{m}\right.$ & & & 0.055 & 0.462 & & & & & & \\
\hline \multicolumn{11}{|l|}{ Dummies } \\
\hline Adj R2 & \multicolumn{2}{|c|}{0.447} & \multicolumn{2}{|c|}{0.459} & \multicolumn{2}{|c|}{0.282} & \multicolumn{2}{|c|}{0.563} & \multicolumn{2}{|c|}{0.339} \\
\hline
\end{tabular}

Note: $Q-O-Q$ core CPI inflation has been adopted for all countries, except Australia, Colombia, Finland, United Kingdom and Luxembourg, for which headline CPI inflation has been chosen.

Source: OECD calculations. 
ECO/WKP(2015)49

Figure A1.1. New estimates of equilibrium unemployment
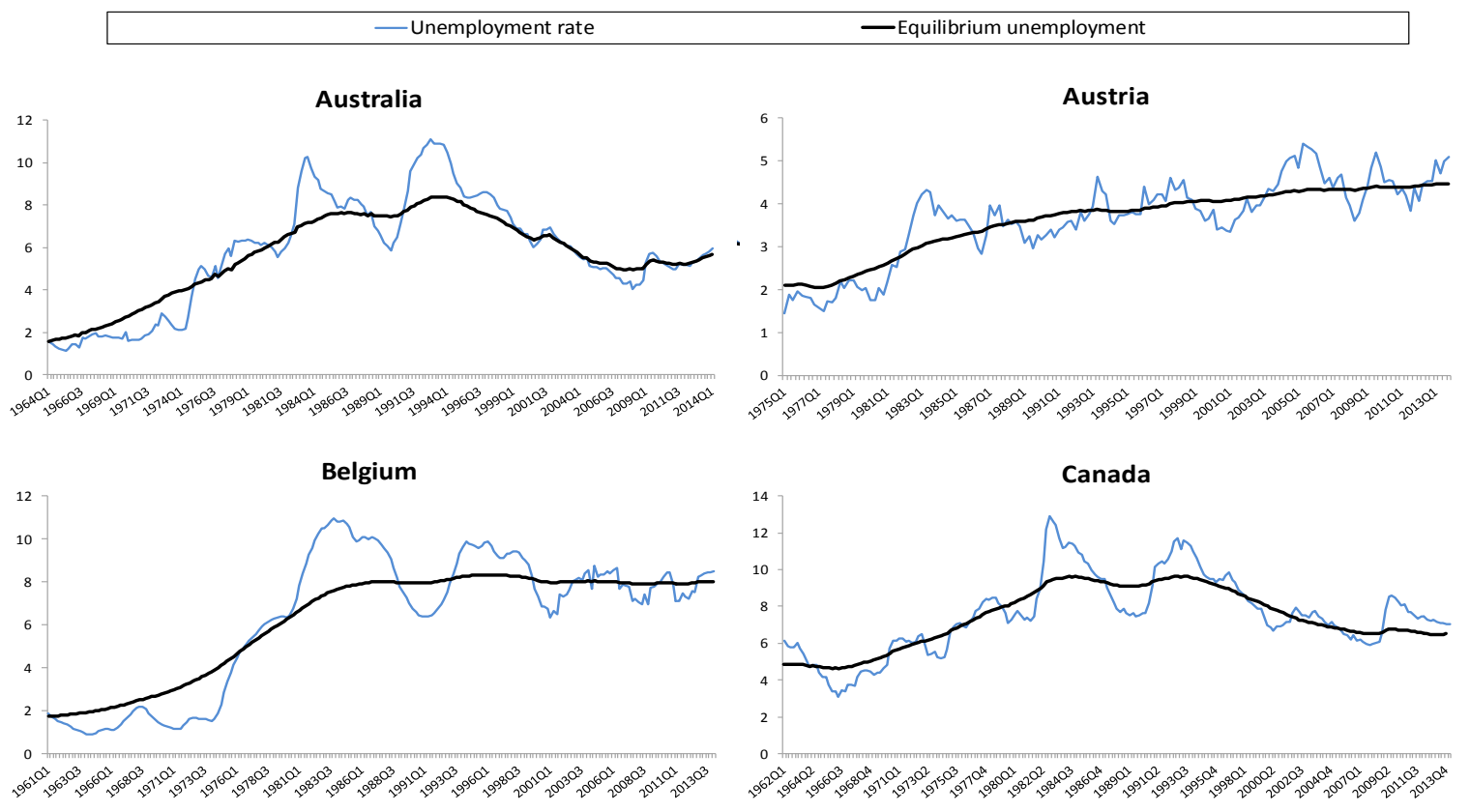

Switzerland

Chile
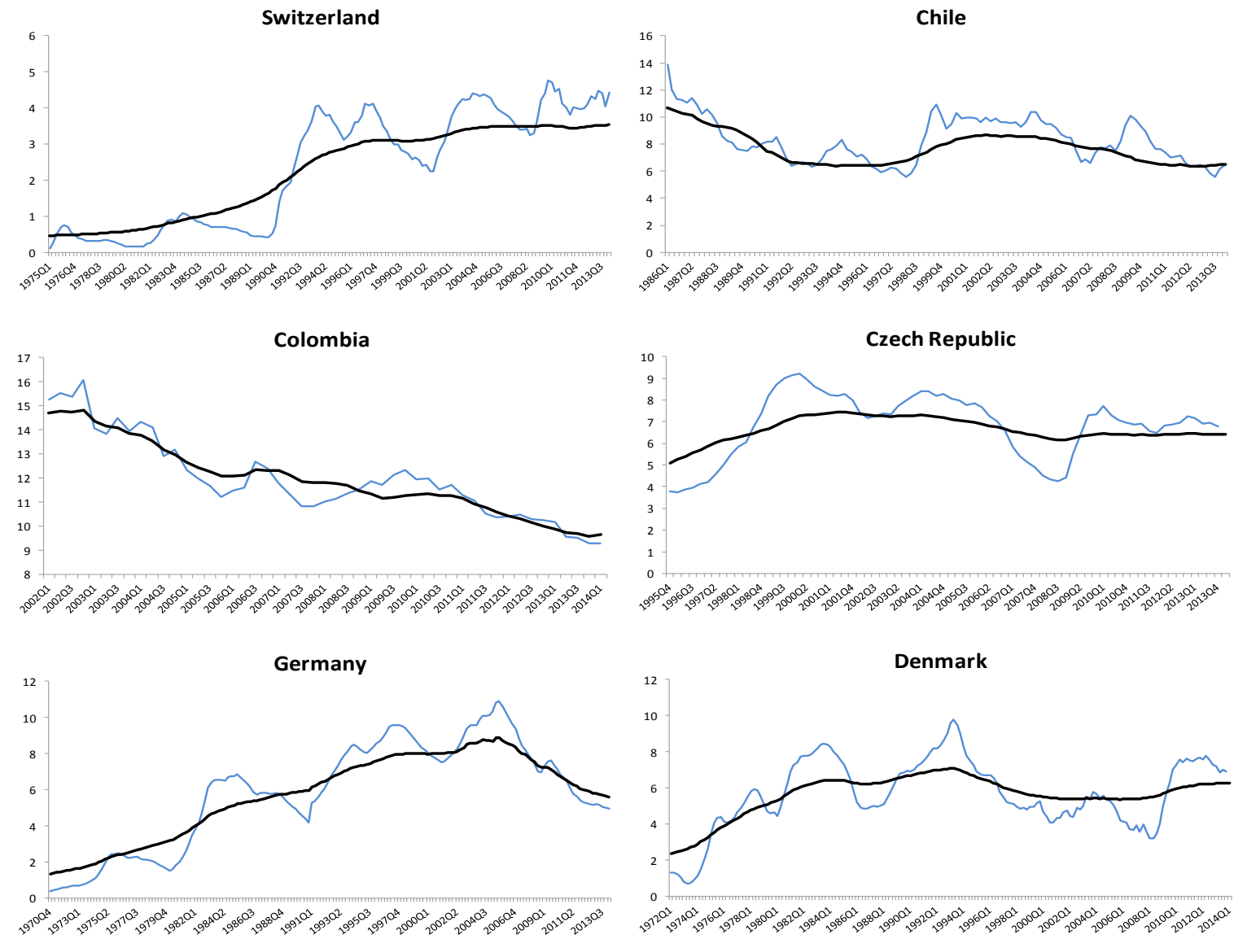

25 
ECO/WKP(2015)49

Spain
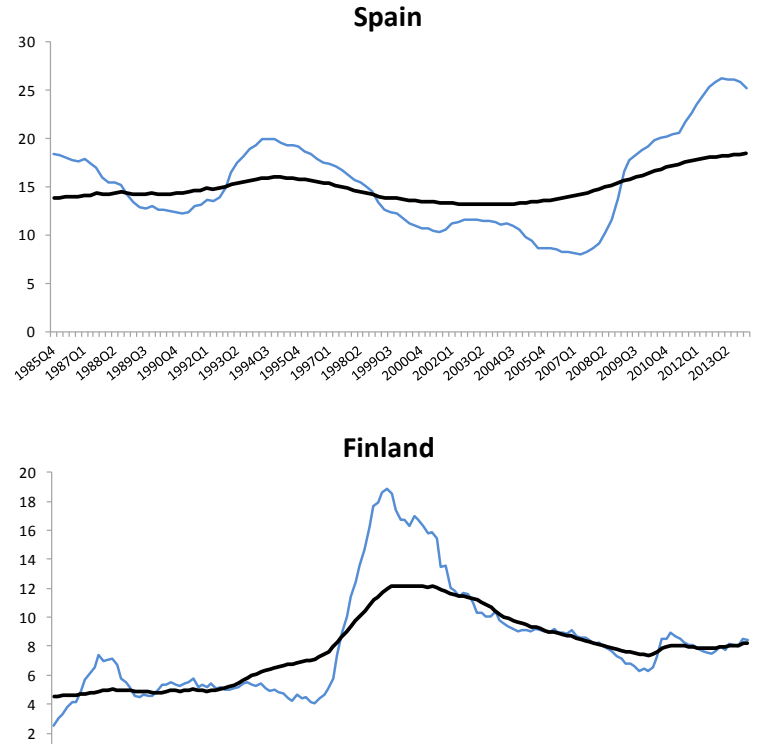
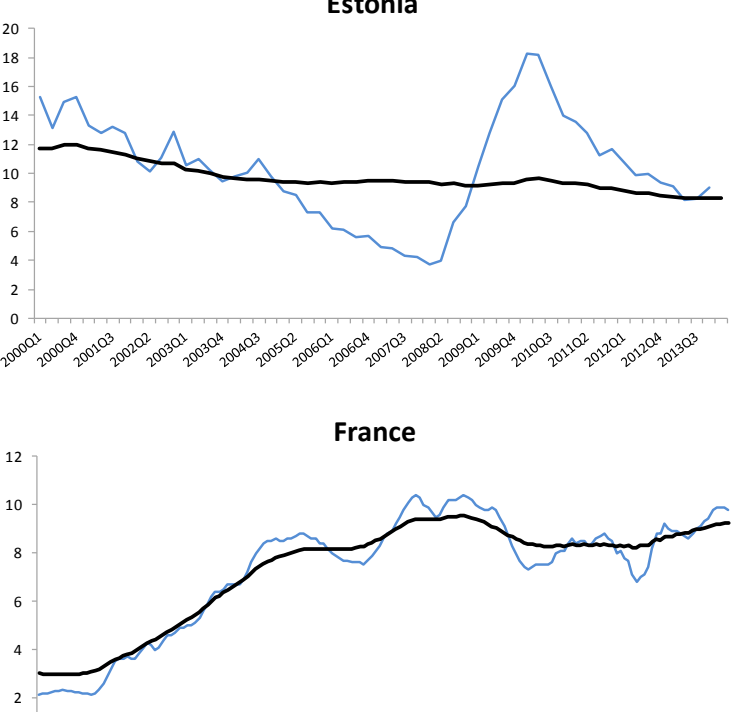

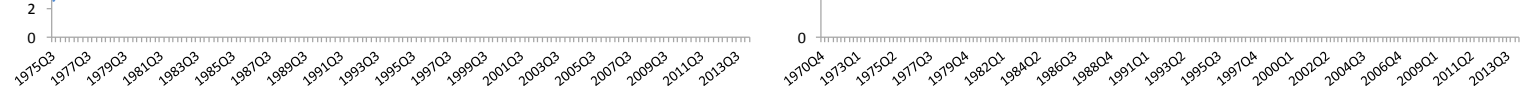
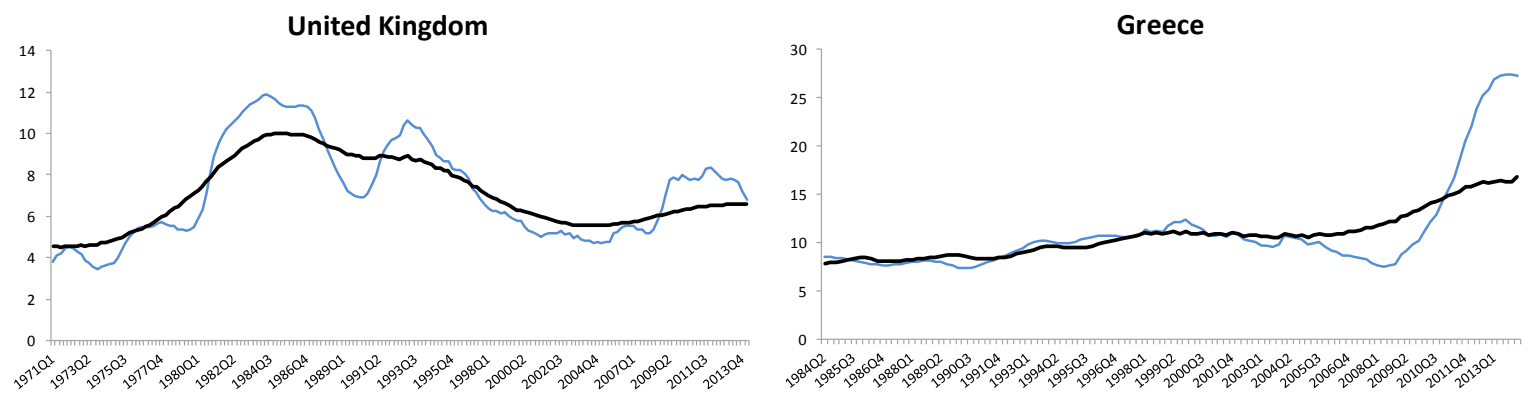

Hungary

Ireland
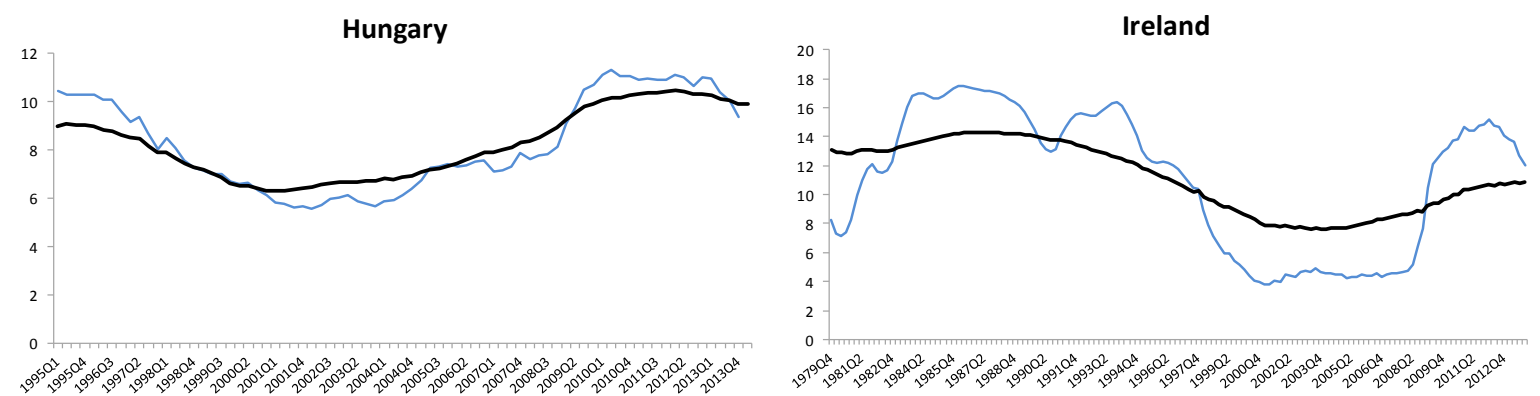

Iceland

Israel

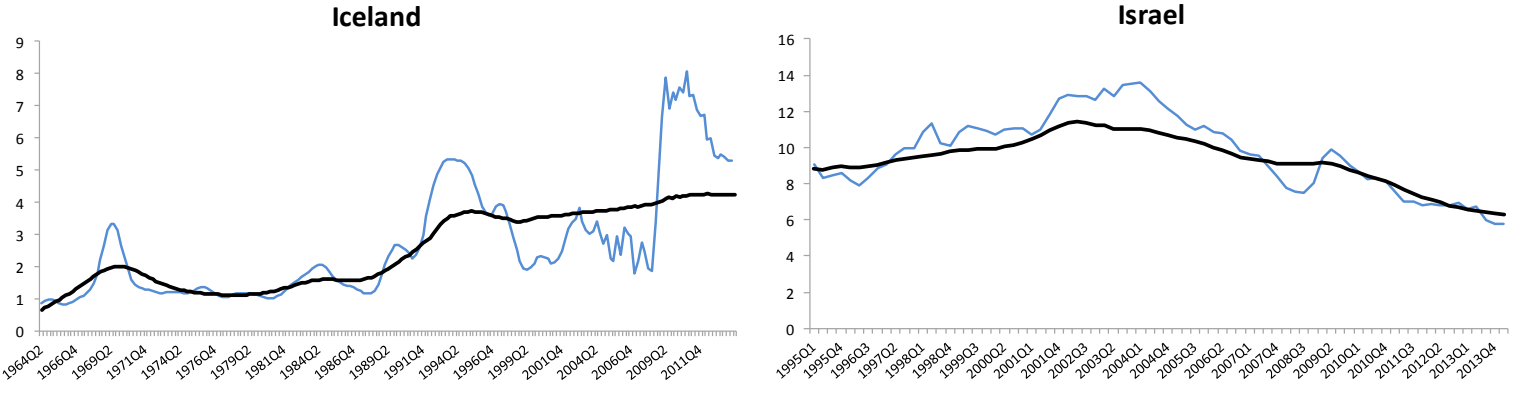

26 
ECO/WKP(2015)49

Italy

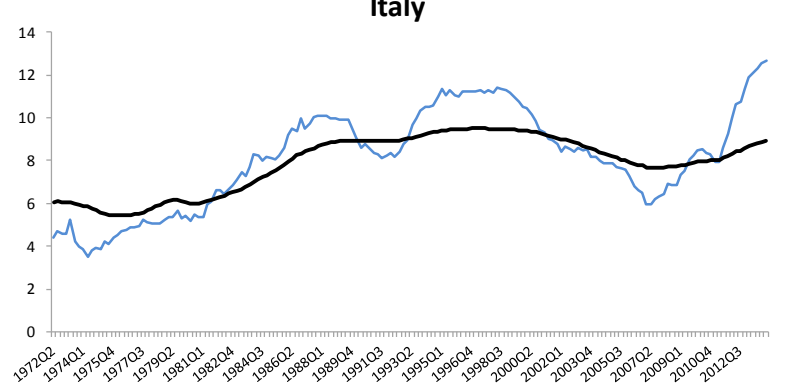

Korea

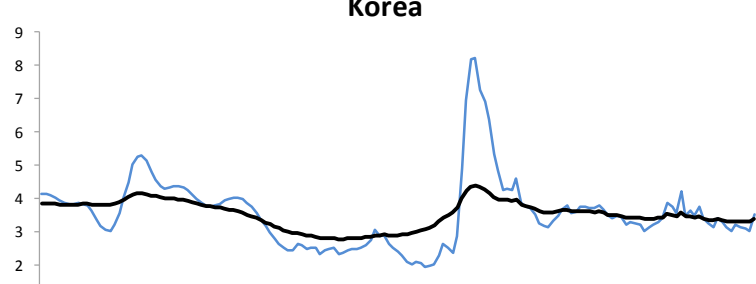

Latvia

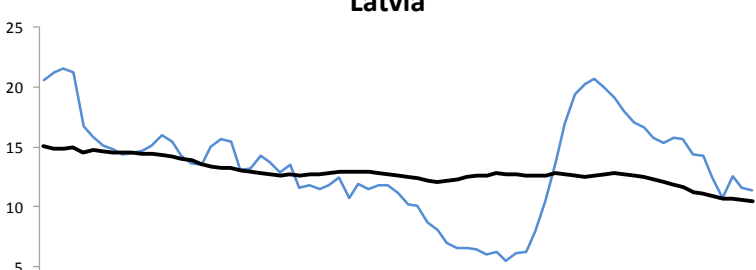

Japan

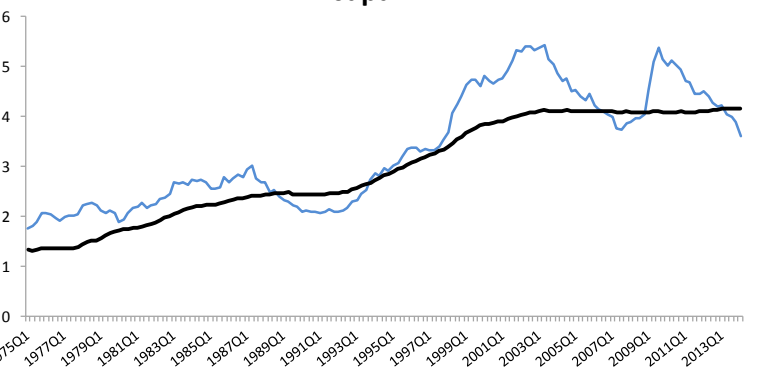

Luxembourg

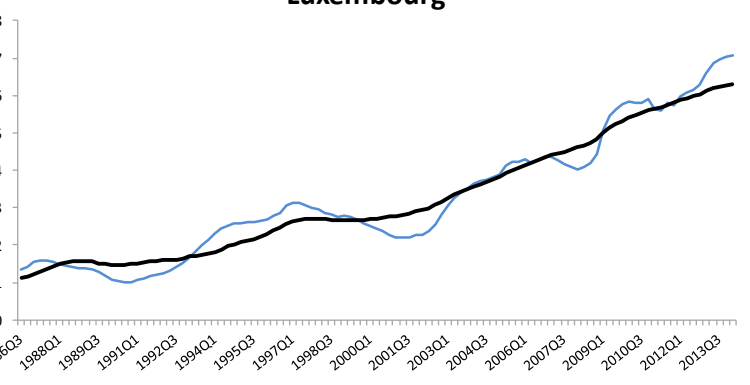

Mexico

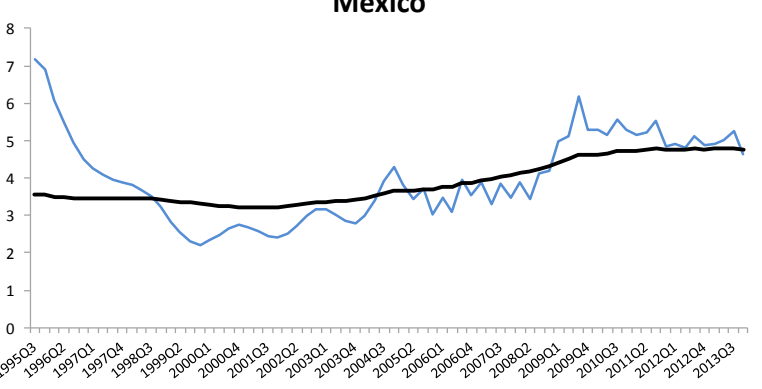

Norway

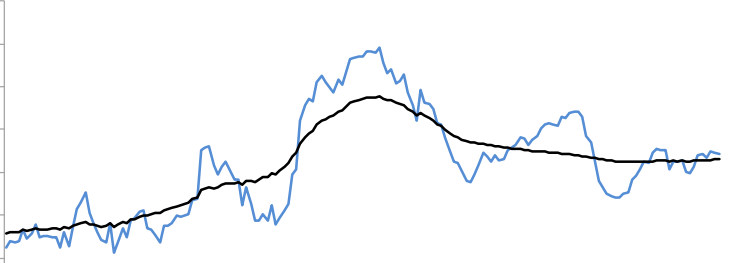

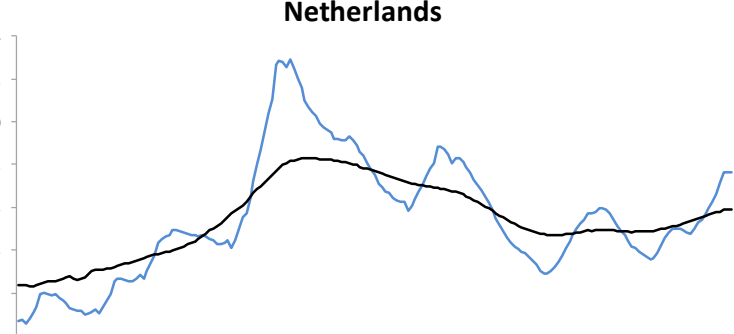
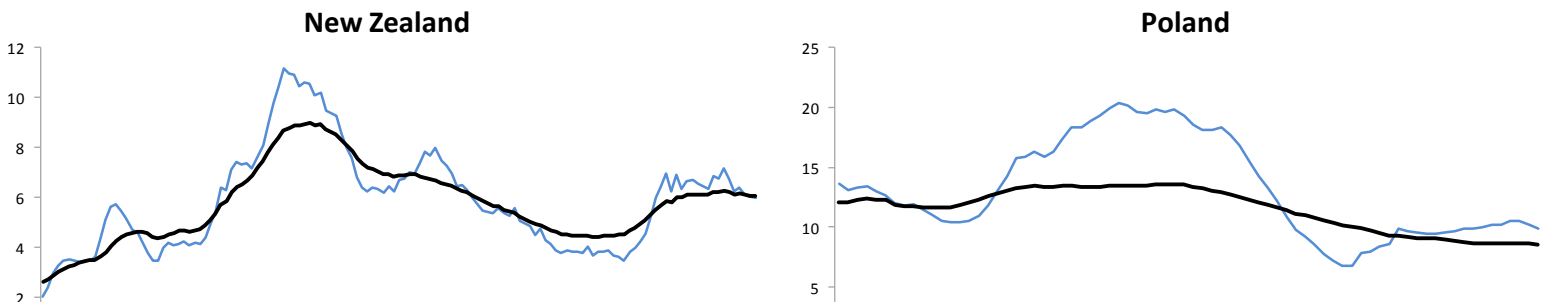

Or is

27 

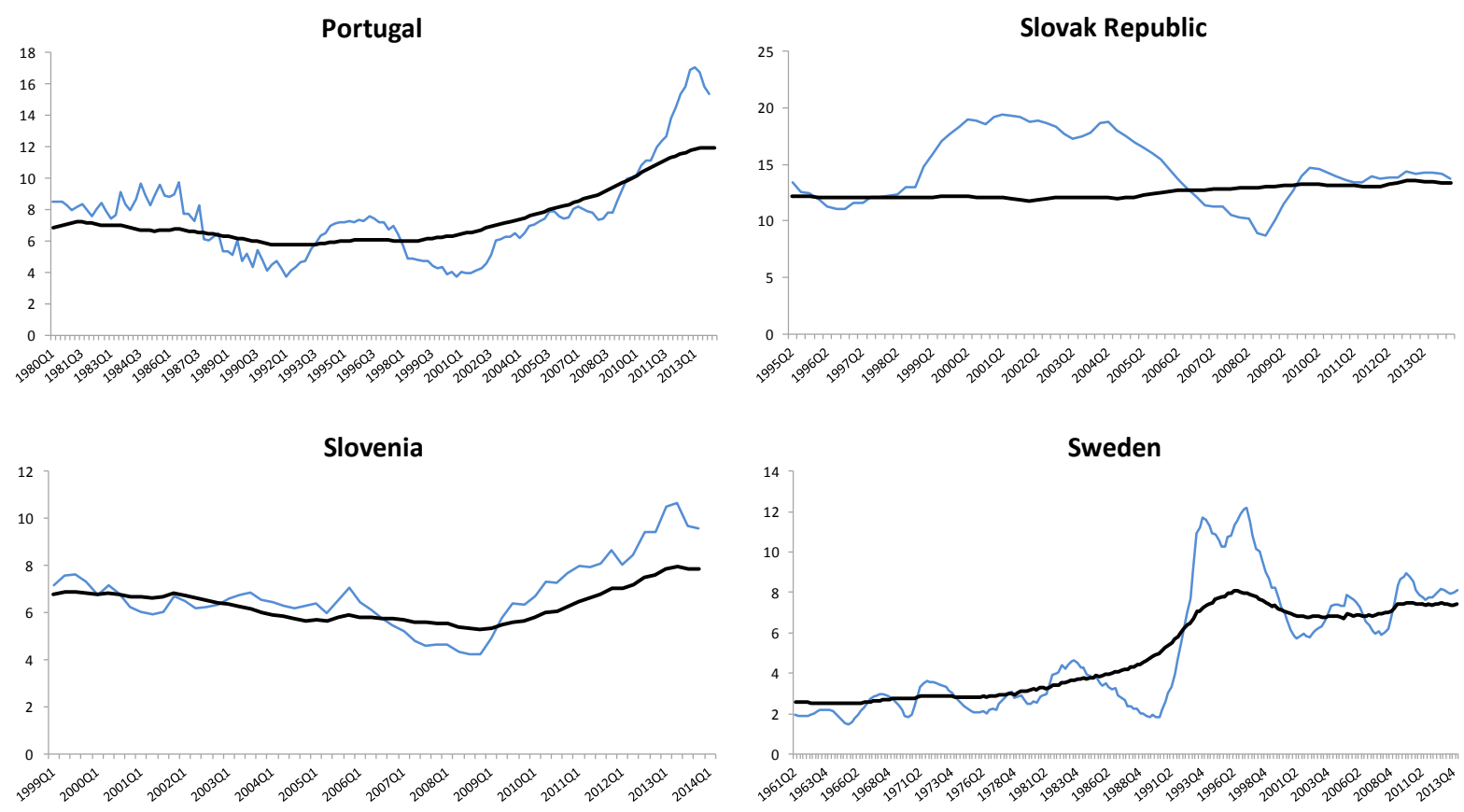

Turkey
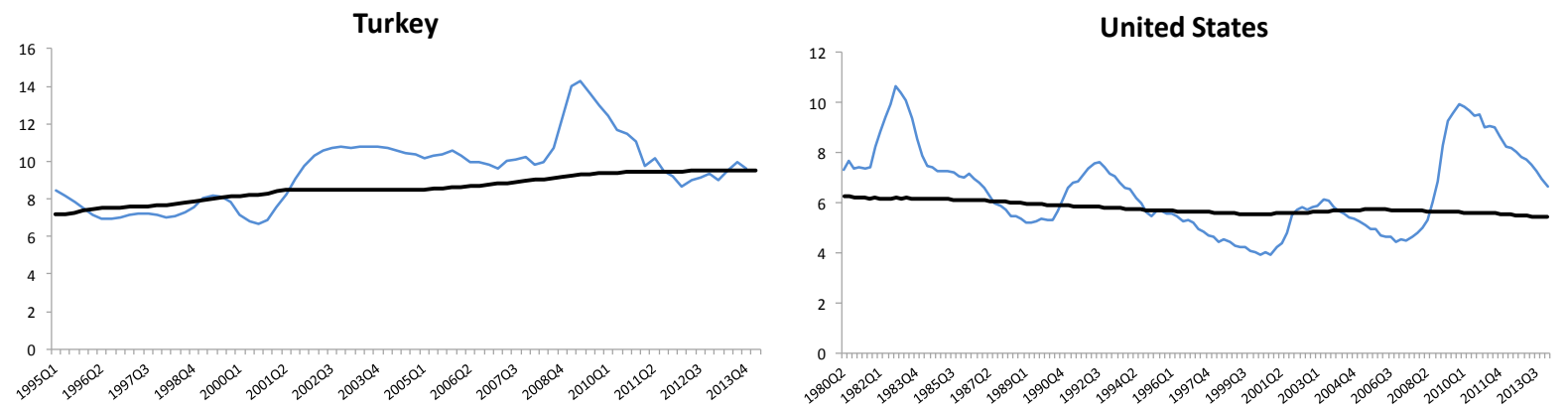

Note: The estimates of the equilibrium unemployment refer to the backward-looking Phillips curve before 1998Q1 and to the anchored expectations Phillips curve from 1998Q1 onwards. For consistency purposes, the initial estimates of equilibrium unemployment in 1998Q1 obtained with the new modelling framework have been constrained to minimise the revision to the existing estimate from the previous method.

Source: OECD Analytical database, and OECD calculations. 


\section{ANNEX 2. FORMAL TESTS OF THE ANCHORING OF INFLATION EXPECTATIONS}

A break in the relationship between long-term inflation expectations and inflation from 1998 (the starting year for the anchored expectations Phillips curve in the main paper) has been investigated for a sample of major OECD countries over the period 1990-2014. The expected level of the headline inflation rate between 6 and 10 years ahead $\pi_{t}^{e}$, based on the semi-annual Survey of Professional Forecasters, has been regressed on lagged headline inflation $\pi_{t-1}$ interacted with a dummy variable $D_{\text {target }}$ which is equal to 1 from 1998 onwards:

$$
\pi_{t}^{e}=\alpha_{1}\left(1-D_{\text {target }}\right) \pi_{t-1}+\alpha_{2} D_{\text {target }} \pi_{t-1}+\alpha_{3} D_{\text {target }}+\varepsilon_{t}
$$

The results suggest that long-term inflation expectations were sensitive to movements in the headline rate of inflation prior to 1998, with estimates of $\alpha_{1}$ statistically significant at the $1 \%$ level for all countries (Table A2.1). Conversely, after 1998 lagged inflation has little explanatory power in explaining long-term inflation expectations. Moreover, after 1998 the coefficient $\alpha_{3}$ is statistically significant and close to $2 \%$ for almost all countries, suggesting relatively well-anchored inflation expectations.

Table A2.1. Estimation results explaining inflation expectations

\begin{tabular}{|cc|c|c|c|c|c|}
\hline & Canada & France & Germany & Italy & $\begin{array}{c}\text { United } \\
\text { Kingdom }\end{array}$ & $\begin{array}{c}\text { United } \\
\text { States }\end{array}$ \\
\hline$\alpha_{1}$ & $0.752^{* * *}$ & $1.140^{* * *}$ & $0.699^{* * *}$ & $0.683^{* * *}$ & $0.701^{* * *}$ & $0.977^{* * *}$ \\
$\alpha_{2}$ & 0.027 & 0.004 & 0.062 & -0.002 & $0.077^{*}$ & -0.020 \\
$\alpha_{3}$ & $1.942^{* * *}$ & $1.832^{* * *}$ & $1.645^{* * *}$ & $1.893^{* * *}$ & $2.159^{* * *}$ & $2.443^{* * *}$ \\
\hline
\end{tabular}

Source: OECD calculations. 


\section{ANNEX 3. SENSITIVITY TO THE TRANSITION VARIANCE CALIBRATION}

To assess the robustness of the results from the anchored expectation approach, sensitivity tests have been performed to alternative choices of the variance $\left(\sigma_{v}^{2}\right)$ of the error term in the random walk equation modelling the equilibrium unemployment $U^{*}(1.4)$. The value of such variance relative to the one of the error term in the Phillips curve equation (1.1) is generally termed signal-to-noise ratio and it controls the smoothness of estimates of equilibrium unemployment. The higher the value of the signal-to-noise ratio, ceteris paribus, the more volatile the estimated U*.

Alternative values of $\sigma_{v}^{2}$ have been tested for a sample of countries where unemployment has recently increased most. The shaded band in Figure A3.1 represents values of the equilibrium unemployment rate that would still generate coefficients on the unemployment gap which are at least as significant as in the preferred Phillips curve equation. Since very low values of $\sigma_{v}^{2}$ would trigger the pile-up problem (see Annex 1), the tests on alternative choices of $\sigma_{v}^{2}$ have considered the restriction that the signal-to-noise ratio always remains within the range of reasonable values identified in the literature (Laubach, 2001; Staiger et al., 1997b). More specifically, the signal-to-noise ratio has been constrained to a range between 0.05 and 0.15, a range first estimated by Staiger et al (1997b) and largely respected by the literature on the NAIRU.

The analysis confirms that estimates of equilibrium unemployment under the anchored expectation specification are sensitive to the choice of the variances of the error terms in the state space equations, particularly towards the end of the estimation sample. However, the margin of this sensitivity does not seem unduly alarming, but rather underlines the importance of having a strongly significant unemployment gap in the Phillips curve. Thus, plausible values for the equilibrium unemployment rate at the end-point of the estimation period (i.e., 2014Q1) remain confined in a range of \pm 1 percentage point on average around the central estimate. 
ECO/WKP(2015)49

Figure A3.1. Sensitivity tests to alternative choices of parameters in the state space equations
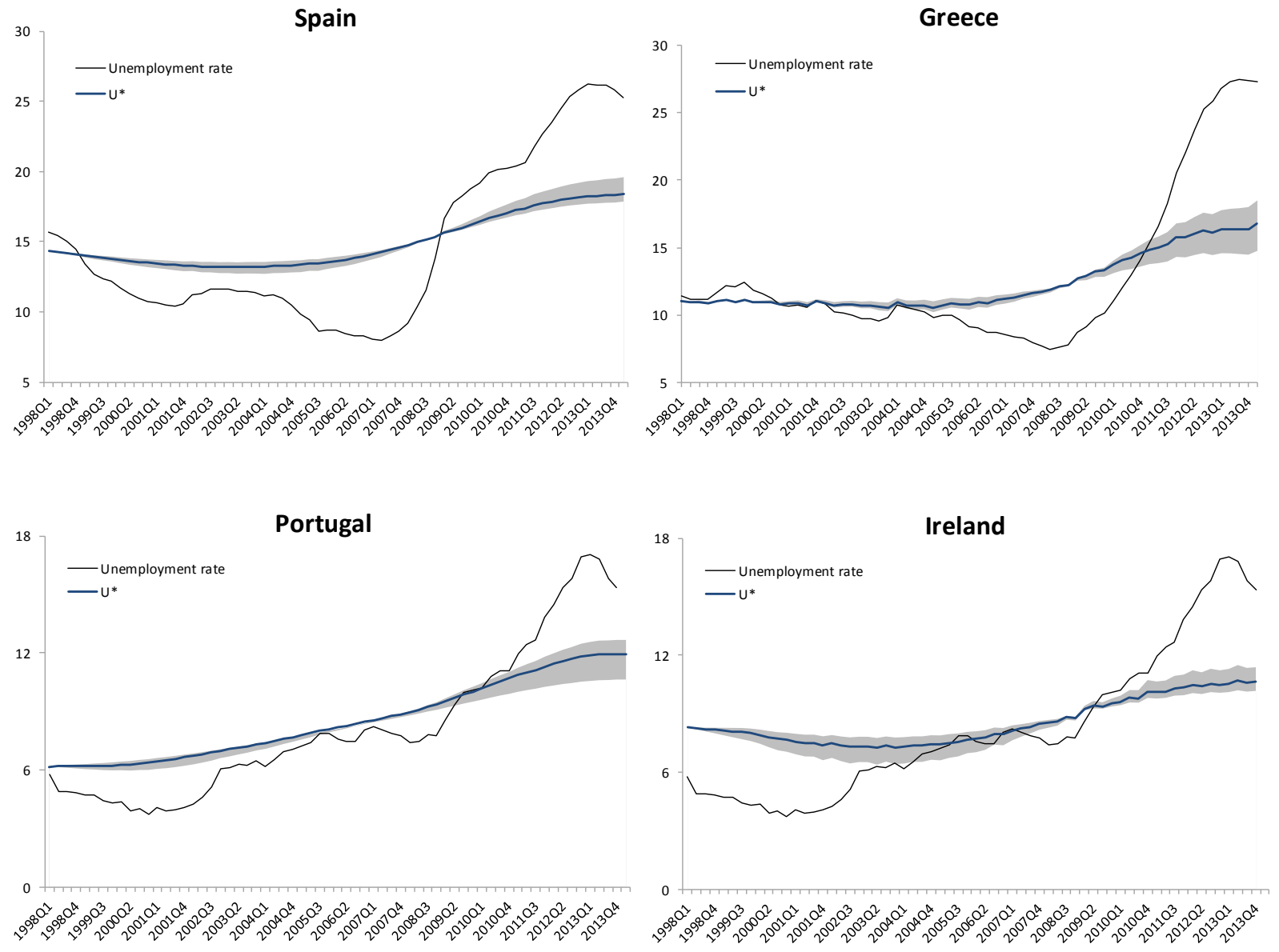

Note: The shaded band shows the range of estimates for the equilibrium unemployment rate obtained by changing the variance parameters in the state space equation, while at the same time maintaining the statistical significance of the unemployment gap in the preferred Phillips curve equation.

Source: OECD calculations.

31 


\section{REFERENCES}

Abritti, M. and S. Fahr (2013), "Downward Wage Rigidity and Business Cycle Symmetries", Journal of Monetary Economics, Vol. 60, pp. 871-886.

Bernanke, B. S. (2004), "Panel Discussion: Inflation Targeting", Federal Reserve Bank of St. Louis Review, Vol. 86(4), pp. 165-68. July/August.

Coibion, C. and Y. Gorodnichennko (2015), "Is the Phillips Curve Alive: and Well after All? Inflation Expectations and the Missing Disinflation", American Economic Journal: Macroeconomics, Vol. 7(1), pp. 197-232.

Daly, M.C., B. Hobijn and T.S. Wiles (2012), "Dissecting Aggregate Real Wage Fluctuations: Individual Wage Growth and the Composition Effect", Federal Reserve Bank of San Francisco Working Paper Series, No. 2011 - 23.

ECB (2014), "The Phillips Curve Relationship in the Euro Area", ECB Monthly Bulletin, Vol.45 pp. 99114. July.

Gianella, C., I. Koske, E. Rusticelli and O. Chatal (2008), "What Drives the NAIRU? Evidence from a Panel of OECD Countries", OECD Economics Department Working Paper, No. 649, OECD Publishing.

Gordon, R.J. (1997), "The time-varying NAIRU and its implications for economic policy", Journal of Economic Perspectives, Vol. 11(1), pp. 11-32.

Guichard, S. and E. Rusticelli (2011), "Reassessing the NAIRUs after the Crisis", OECD Economics Department Working Paper, No. 918, OECD Publishing.

Hooker, M., (2002), Are Oil Shocks Inflationary? Asymmetric and Nonlinear Specifications versus Changes in Regime, Journal of Money, Credit and Banking, Vol. 34, issue 2, p. 540-61.

IMF (2013), "The dog that didn't bark: has inflation been muzzled or was it just sleeping", World Economic Outlook, IMF, April.

Jaeger, A. and M. Parkinson (1994), "Some Evidence on Hysteresis in Unemployment Rates", European Economic Review, No. 38, pp. 329-342.

Laubach, T. (2001), "Measuring the NAIRU: Evidence from Seven Economies", The Review of Economics and Statistics, Vol. 83(2), pp. 218-231.

Llaudes, R. (2005), "The Phillips Curve and Long-Term Unemployment”, European Central Bank Working Paper Series, No. 441.

OECD (2014), OECD Employment Outlook 2014, OECD Publishing.

Rusticelli, E. (2014), "Rescuing the Phillips Curve: Making Use of Long-term Unemployment in the Measurement of the NAIRU”, OECD Journal: Economics Studies, Vol. 2014. 
Staiger, D., J. H. Stock and M.W. Watson (1997a), "The NAIRU, Unemployment, and Monetary Policy", Journal of Economic Perspectives, Vol. 11(1), pp. 33-51.

Staiger, D., J. H. Stock and M.W. Watson (1997b), "How Precise Are Estimates of the Natural Rate of Unemployment?" in: Romer, C. D. and D. H. Romer, (eds.), Reducing Inflation: Motivation and Strategy, University of Chicago Press.

Stevens, A. (2014), "What Inflation Developments Reveal about the Phillips Curve: Implications for Monetary Policy", National Bank of Belgium Economic Review, Vol. 2013(III), pp.67-76.

Stock, J. H. (1994), “Unit Roots, Structural Breaks, and Trends", Handbook of Econometrics, Vol. 4, pp. 2739-2841.

Thornton, D. L. (2007), “The Lower and Upper Bounds of the Federal Open Market Committee's LongRun Inflation Objective", Federal Reserve Bank of St. Louis Review, Vol. 89(3), pp. 183-93. May/June

Yellen, J. L. (2012), “Perspectives on Monetary Policy,” speech at the Boston Economic Club, June. 


\section{WORKING PAPERS}

The full series of Economics Department Working Papers can be consulted at www.oecd.org/eco/workingpapers

1230. Macroeconomic uncertainties, prudent debt targets and fiscal rules,

(July 2015) by Falilou Fall and Jean-Marc Fournier

1229. Limits to government debt sustainability

(July 2015) by Jean-Marc Fournier and Falilou Fall

1228. Government debt indicators: understanding the data

(July 2015) by Debbie Bloch and Falilou Fall

1227. The costs of flexibility-enhancing structural reforms: a literature review

(July 2015) by Tito Boeri, Pierre Cahuc and André Zylberberg

1226. Household finance and income inequality in the euro area

(June 2015) Oliver Denk and Alexandre Cazenave-Lacroutz

1225. Financial sector pay and labour income inequality: evidence from Europe

(June 2015) by Oliver Denk

1224. Finance and income inequality in OECD countries

(June 2015) by Oliver Denk and Boris Cournède

1223. Finance and economic growth in OECD and G20 countries

(June 2015) by Boris Cournède and Oliver Denk

1222. What impedes household investment in energy efficiency and renewable energy?

(May 2015) by Nadia Ameli and Nicola Brandt

1221. Recent trends in productivity in China - shift-share analysis of labour productivity growth and the evolution of the productivity gap

(May 2015) by Margit Molnar and Thomas Chalaux

1220. Assessing China's skills gap and inequalities in education

(May 2015) by Margit Molnar, Boqing Wang and Ruidong Gao

1219. Providing the right skills to all in China-from "made in China" to "created in China"

(May 2015) by Margit Molnar and Vincent Koen

1218. Agricultural reforms and bridging the gap for rural China

(May 2015) by Ben Westmore

1217. A snapshot of China's service sector

(May 2015) by Margit Molnar and Wei Wang

1216. Does the post-crisis weakness of global trade solely reflect weak demand?

(May 2015) by Patrice Ollivaud and Cyrille Schwellnus

1215. Estonia: raising productivity and benefitting more from openness 
(May 2015) by Andreas Kappeler

1214. Estonia: making the most of human capital

(May 2015) by Andrés Fuentes Hutfilter

1213. The Czech labour market: documenting structural change and remaining challenges (May 2015) by Sónia Araújo and Petr Malecek

1212. Reforming the Slovak public sector

(April 2015) by Lilas Demmou and Robert Price

1211. Spurring growth in lagging regions in the Slovak Republic

(April 2015) by Lilas Demmou, Gabriel Machlica, Martin Haluš and Robert Menkyna

1210. Skill mismatch and public policy in OECD countries

(April 2015) by Müge Adalet McGowan and Dan Andrews

1209. Labour market mismatch and labour productivity: evidence from PIAAC data

(April 2015) by Müge Adalet McGowan and Dan Andrews

1208. Maintaining an efficient and equitable housing market in Belgium

(April 2015) by Sanne Zwart

1207. Determinants of the low female labour force participation in India

(April 2015) by Piritta Sorsa, Jan Mares, Mathilde Didier, Caio Guimaraes, Marie Rabate,

Gen Tang and Annamaria Tuske

1206. Strengthening skill use and school-to-work transitions in the Czech Republic

(April 2015) by Sónia Araújo and Petr Malecek

1205. Reforming the tax on immovable property: taking care of the unloved

(April 2015) by Hansjörg Blöchliger

1204. Taxation and investment in Colombia

(April 2015) by Sarah Perret and Bert Brys

1203. Efficiency and contestability in the Colombian banking system

(April 2015) by Christian Daude and Julien Pascal

1202. Fiscal decentralisation in Colombia: new evidence regarding sustainability, risk sharing and "fiscal fatigue"

(April 2015) by Guillaume Bousquet, Christian Daude and Christine de la Maisonneuve

1201. Effects of economic policies on microeconomic stability

(April 2015) by Boris Cournède, Paula Garda and Volker Ziemann

1200. The 2013 update of the OECD's database on product market regulation - policy insights for $O E C D$ and non-OECD countries

(April 2015) by Isabell Koske, Isabelle Wanner, Rosamaria Bitetti and Omar Barbiero 